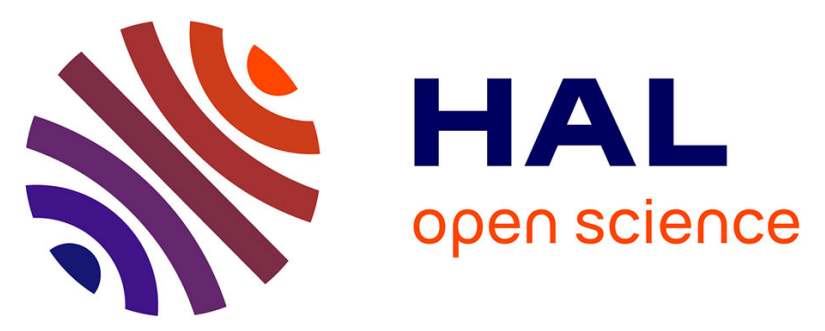

\title{
Sensitivity of the retrieval of the inherent optical properties of marine particles in coastal waters to the directional variations and the polarization of the reflectance
}

Malik Chami, Michael Defoin Platel

\section{To cite this version:}

Malik Chami, Michael Defoin Platel. Sensitivity of the retrieval of the inherent optical properties of marine particles in coastal waters to the directional variations and the polarization of the reflectance. JOURNAL OF GEOPHYSICAL RESEARCH-OCEANS, 2007, 112 (C5), 10.1029/2006JC003758 . hal-03504946

\section{HAL Id: hal-03504946 \\ https://hal.science/hal-03504946}

Submitted on 31 Dec 2021

HAL is a multi-disciplinary open access archive for the deposit and dissemination of scientific research documents, whether they are published or not. The documents may come from teaching and research institutions in France or abroad, or from public or private research centers.
L'archive ouverte pluridisciplinaire HAL, est destinée au dépôt et à la diffusion de documents scientifiques de niveau recherche, publiés ou non, émanant des établissements d'enseignement et de recherche français ou étrangers, des laboratoires publics ou privés. 


\title{
Sensitivity of the retrieval of the inherent optical properties of marine particles in coastal waters to the directional variations and the polarization of the reflectance
}

\author{
Malik Chami ${ }^{1}$ and Michael Defoin Platel $^{1,2}$ \\ Received 14 June 2006; revised 15 December 2006; accepted 9 January 2007; published 17 May 2007. \\ [1] The influences of the directional variations and the polarization of the marine \\ reflectance on the retrieval of the inherent optical properties (IOP) (i.e., absorption, \\ scattering, and backscattering coefficients) of water constituents in coastal waters \\ are examined. First, an inversion algorithm based on artificial neural network (NN) \\ methodology is developed using a synthetic data set. The simulations were carried out \\ using a radiative transfer model that accounts for the polarization state of light in the \\ ocean. The simulated data included various directional effects of the particles. The data set \\ is also constrained by observations collected in optically representative coastal waters. \\ In particular, the relationships that exist between the IOP were taken into account, thus \\ making the data set realistic. The results showed that the total IOP were correctly retrieved \\ while the performance of the algorithm to derive the IOP of each water component \\ significantly degrades. However, the inclusion of the directional variations and the \\ polarization of the reflectance in the algorithm improved the accuracy of retrieval of \\ the scattering properties by $15 \%-60 \%$ and $65 \%-75 \%$, respectively. The phytoplankton \\ and noncovarying particles (i.e., nonalgal particles) scattering and backscattering \\ coefficients were derived with an accuracy of $25 \%$ and $15 \%$ respectively. These results \\ demonstrate the potential of using the polarized signal to separate the total IOP into \\ contribution of biogenic and highly refractive particles in coastal waters. Therefore \\ the development of in situ instrumentation able to measure the polarization properties \\ of the particles is recommended.
}

Citation: Chami, M., and M. D. Platel (2007), Sensitivity of the retrieval of the inherent optical properties of marine particles in coastal waters to the directional variations and the polarization of the reflectance, J. Geophys. Res., 112, C05037, doi:10.1029/2006JC003758.

\section{Introduction}

[2] In the past, the emphasis of ocean color remote sensing was focused on the derivation of the chlorophyll concentration. This is partly because chlorophyll plays a central role in conventional algorithms for primary production or light attenuation coefficients. But, fundamentally, water color is determined by the inherent optical properties (IOP) of the water constituents (namely the absorption, scattering, and backscattering coefficients), and chlorophyll is just one of the active components that determine the IOP. Previous studies, as outlined in the report 3 of the International Ocean Colour Coordinating Group (IOCCG) [International Ocean Colour Coordinating Group (IOCCG), 2000], have emphasized the importance

\footnotetext{
${ }^{1}$ Laboratoire Océanographie de Villefranche, Villefranche sur Mer, France.

${ }^{2}$ Laboratoire d'Informatique Signaux et Systèmes de Sophia Antipolis, Université de Nice-Sophia Antipolis, Sophia Antipolis, France.

Copyright 2007 by the American Geophysical Union. 0148-0227/07/2006JC003758
}

of understanding and retrieving IOP in ocean color remote sensing. IOP are at the center of satellite-measured water leaving radiance and optically active marine components (i.e., phytoplankton, minerals, and dissolved matter). At the same time, variations of IOP are clear indications of changes of water mass or marine components. Therefore the inverse problem of ocean color, which consists in determining the biogeochemical parameters from the upwelling radiance spectrum, can be examined as a two-step process: the derivation of IOP from the radiance and then biogeochemical parameters from the IOP. Such an IOP-based inversion maximizes the information gained from remote sensing. Recently, good progress has been made in the inversion of IOP from the upwelled radiance spectrum [Roesler and Perry, 1995; Lee et al., 1996a; Garver and Siegel, 1997; Hoge and Lyon, 1996; Carder et al., 1999; Lee et al., 2002; Maritorena et al., 2002; Roesler and Boss, 2003]. Nevertheless, significant efforts still need to be done when dealing with optically complex waters such as those encountered in coastal zones. Most of the current inversions algorithms are based on the following relationship 
(equation (1)), which was derived from radiative transfer calculations:

$$
\operatorname{Rrs}\left(0^{-}\right)=L_{\mathrm{u}}\left(0^{-}\right) / E_{\mathrm{d}}\left(0^{-}\right)=g \frac{b_{\text {btot }}}{a_{\text {tot }}}
$$

where $\operatorname{Rrs}\left(0^{-}\right)$is the subsurface remote sensing reflectance, defined by the ratio of nadir-viewed upwelling radiance $L_{\mathrm{u}}\left(0^{-}\right)$(in $\mathrm{W} \mathrm{m}^{-2} \mathrm{sr}^{-1}$ ) to downwelling irradiance $E_{\mathrm{d}}\left(0^{-}\right)$ (in $\mathrm{W} \mathrm{m}^{-2}$ ) just beneath the sea surface, $b_{\text {btot }}$ is the total backscattering coefficient (in $\mathrm{m}^{-1}$ ), $a_{\mathrm{tot}}$ is the total absorption coefficient (in $\mathrm{m}^{-1}$ ), and $g$ is a proportionality factor $\left(\mathrm{sr}^{-1}\right)$. The directional effects of radiative transfer (viewing geometry and volume scattering function of particles) are contained in the factor $g$. Previous studies [Morel and Gentili, 1996; Morel et al., 2002] proposed a parameterization of $g$ as a function of chlorophyll concentration in open ocean waters. Such a parameterization is clearly not applicable in coastal waters since IOP are not determined by chlorophyll. Furthermore, constant values of $g$ are often employed in practice, regardless of the positions of the sun and sensor. Recently, Albert and Mobley [2003] and Park and Ruddick [2005] proposed a reflectance model able to represent the bidirectional properties of waters for which the backscatter coefficient is not determined entirely by chlorophyll. Improved model accuracy was shown by the inclusion of the bidirectionality. However, Zaneveld [1973] previously showed that, in theory, the inversion of the entire radiance distribution is necessary to obtain exact values of IOP. Uncertainties in the derivation of IOP are currently introduced anytime inversion formulas such as equation (1) approximation are used. Therefore a significant improvement of accuracies of the inversion necessitates the consideration of directional effects such as the multidirectionality of the reflectance, as evidenced by several studies on the bidirectional reflectance [Morel and Gentili, 1996; Albert and Mobley, 2003; Park and Ruddick, 2005]. Currently, the measurement of the radiance is practically carried out in one direction (mainly at nadir when dealing with in situ measurements) in remote sensing. Thus, the directional variations of the Rrs (i.e., multidirectional reflectance) are still ignored in inversion algorithms.

[3] Another piece of physical information that is neglected in the current inversion algorithms is the contribution of the polarization state of light. The radiative transfer models that are currently used to express the reflectance as a function of IOP (such as Hydrolight [Mobley, 1989], Coupled Discrete Ordinate Radiative Transfer (CDISORT) [Jin and Stamnes, 1994], or Monte Carlo [Morel and Gentili, 1996]) solves the scalar radiative transfer equation and, thus, they do not account for the polarization of the radiation. Yet Chami et al. [2001], who investigated the influence of the marine particles on both the directional structure and the polarization state of light, showed that the polarized reflectance is strongly affected by the hydrosols in coastal waters.

[4] In this paper, we investigate the influence of the directional structure and the polarization of the remote sensing reflectance on the performance of an inversion algorithm. Our major goal is thus to quantify the improve- ment in accuracy of the IOP retrieval in coastal waters when the directional variations and the polarization of the reflectance are accounted for. First, we describe the inversion algorithm and the simulation conditions used to generate a synthetic data set. The sensitivity of the IOP retrieval to the directionality and polarization of the oceanic radiation is then presented and discussed.

\section{Inversion Algorithm}

[5] The algorithm which is applied in this study is a neural network (NN) inversion procedure. The NN procedure was selected because of its capability to invert directional remote sensing reflectance directly into absorption and scattering coefficients of different constituents as present in coastal waters [Schiller and Doerffer, 2005]. Neural networks consist of a large number of "neurons", i.e., simple linear or nonlinear computing elements, interconnected in complex ways and often organized into layers. Here a feedforward multilayer perceptron was developed. In this type of $\mathrm{NN}$, the data flow through the network in one direction from an input layer to an output layer through at least one hidden layer. The function of the hidden layer is to enable the network to extract higher order statistics, which is particularly valuable when the size of the input layer is large. The complexity of feedforward multilayer perceptrons can vary according to their topologies (i.e., the number of hidden layers and the number of neurons in each hidden layer). The input to each layer is the weighted sum of the outputs of the previous layer. This sum is passed through a nonlinear activation function to generate the output. The function that was adopted here is the sigmoid function, which is by far the most common form of activation function used in the construction of NNs for solving nonlinear regression tasks. To ensure that the NN will produce the expected function, the strength of the connections within the network, called connections weights, has to be determined. To achieve this task, the neural network needs to be educated through a set of examples, the so-called training cases. A training case consists of presenting to the $\mathrm{NN}$ an input vector and the associated expected output vector. In practice, we train the system by iterative adjustment of the connection weights. For this study, the standard back propagation learning algorithm was used. This algorithm modifies the connection weights to reduce the difference between the desired and the actual output values of the network. To ensure that the NN works also well on unseen data, classical techniques that promote the generalization of the model were used such as weight decay [Krogh and Hertz, 1992] and cross-validation [Geisser, 1975].

\section{Radiative Transfer Simulations}

[6] The neural network was trained with simulated $\operatorname{Rrs}\left(0^{-}\right)$spectra. About 10,000 spectra were simulated to cover a large variety of optical coastal water conditions. One half of these spectra were used for the training phase, while the other half were used for the validation of the algorithm. The simulations were performed using the Ordre Sucessifs Ocean Atmosphere (OSOA) radiative transfer model [Chami et al., 2001]. The OSOA model 
solves the vector radiative transfer equation for the coupled atmosphere-ocean system using the successive orders of scattering method. Given a set of IOP in the water column, the OSOA model outputs the angular distribution of the radiance field and its degree of polarization. The originality of OSOA model, when comparing to other widely used models such as Hydrolight, is to account for the polarization state of light in the water mass. As a result, it was not relevant in this study to use the synthetic data set generated in the framework of the IOCCG working group [International Ocean Colour Coordinating Group (IOCCG), 2006], which is based on Hydrolight simulations.

[7] We report here on the input parameters used in the OSOA model. Standard atmosphere with tropospheric aerosols T70 [Shettle and Fenn, 1979] having an optical depth of 0.2 at $555 \mathrm{~nm}$ (i.e., horizontal visibility of $23 \mathrm{~km}$ ) was used to simulate the incoming solar light. The solar zenith angle was set up to $30^{\circ}$ in air. The remote sensing reflectance was simulated just beneath the surface for different scattering angles, namely from $110^{\circ}$ to $170^{\circ}$. We selected this range of scattering angle to be consistent with the multidirectional measurements of the satellite sensor Polarization and Anisotropy of Reflectances for Atmospheric Sciences Coupled with Observations From a Lidar (PARASOL) (Centre National d'Etudes Spatiales (CNES)), which is the only one that is currently able to measure the multidirectional and polarized reflectance. Note that the nadir remote sensing reflectance corresponds to a scattering angle of $158^{\circ}$. The wavelengths used to compute the total Rrs (i.e., total means unpolarized) were $412,443,490,510,555,620$, and $665 \mathrm{~nm}$. The polarized Rrs was computed at 490 and 665 $\mathrm{nm}$ to match with the polarized channels of the PARASOL satellite sensor.

[8] The IOP required for the simulation are the absorption coefficients, the scattering coefficients, and the phase function of the particles. For computation of the IOP, a four-component seawater model is considered. The four components are pure seawater, phytoplankton and their covarying particles, colored dissolved organic matter $(\mathrm{CDOM})$, and noncovarying particles. In the notation for IOP, these components are indicated by subscripts $\mathrm{w}, \mathrm{ph}$, $\mathrm{CDOM}$, and $\mathrm{NC}$, respectively. In this water model, the total absorption coefficient $a_{\text {tot }}$ is the sum of contributions from the four components. Since CDOM is supposed to be nonscattering material, the total scattering coefficient $b_{\text {tot }}$ and backscattering coefficient $b_{\text {btot }}$ are the sum of the three following components: water, phytoplankton, and noncovarying particles.

\subsection{Absorption and Scattering Optical Models}

[9] The spectral data of $a_{\mathrm{w}}$ were taken from Pope and Fry [1997]. Spectral CDOM absorption was modeled as Bricaud et al. [1981]:

$$
a_{\mathrm{CDOM}}(\lambda)=a_{\mathrm{CDOM}}(443) \exp \left[-S_{\mathrm{CDOM}}(\lambda-443)\right]
$$

The spectral absorption of noncovarying particles was modeled as in the study of Babin et al. [2003a] (equation (3)):

$$
a_{\mathrm{NC}}(\lambda)=a_{\mathrm{NC}}(443) \exp \left[-S_{\mathrm{NC}}(\lambda-443)\right]
$$

The spectral scattering coefficients of phytoplankton and noncovarying particles were modeled as (equations (4) and (5)):

$$
\begin{aligned}
& b_{\mathrm{ph}}(\lambda)=b_{\mathrm{ph}}(443)\left(\frac{\lambda}{443}\right)^{-S_{\mathrm{bph}}} \\
& b_{\mathrm{NC}}(\lambda)=b_{\mathrm{NC}}(443)\left(\frac{\lambda}{443}\right)^{-S_{\mathrm{bNC}}}
\end{aligned}
$$

The spectral variation of the total particulate scattering coefficient $b_{\mathrm{p}}$ also follows a power law function with a slope $S_{\mathrm{bp}}$.

[10] The backscattering coefficient of each optical water components was derived from the scattering coefficient and the integration of the phase function in the backward hemisphere. In coastal waters, the use of several phase functions is required to account for the variability of the optical properties of particles. In this study, the phase functions of particles were computed using Mie theory and different refractive indices for the phytoplankton and noncovarying particles. The size distribution of the particles was modeled as a Junge power law.

\subsection{Selection of the Optical Parameters}

[11] The part controlling the success of the simulations and training of the $\mathrm{NN}$ is the consistency of the data set with observations. In this study, the values of the optical parameters used in the IOP models were based on the measurements of the inherent optical coefficients collected during the Coastal Surveillance Through Observation of Ocean Colour (COASTIOOC) experiment [Babin et al., 2003a, 2003b]. The COASTIOOC data, which were acquired in many European coastal waters (387 data in total), are highly appropriate inasmuch as they cover a wide variety of optical conditions, ranging from CDOM-dominated waters (such as the Baltic Sea) to mineral-dominated waters (such as the English Channel). For each case of simulations, the optical properties are randomly selected within a realistic range of variations based on the COASTIOOC observations (Table 1). The vertical distribution of the water constituents was taken to be homogeneous. The scattering and absorption coefficients of each water component were first randomly selected at the reference wavelength $443 \mathrm{~nm}$. Because the contributions of phytoplankton and noncovarying particles to the total particle scattering coefficient $b_{\mathrm{p}}$ were unknown during the COASTIOOC experiment (only $b_{\mathrm{p}}$ was measured), we randomly selected a value of $b_{\mathrm{p}}(443)$. Then, the contribution of phytoplankton to the total scattering coefficient (i.e., $b_{\mathrm{ph}} / b_{\mathrm{p}}$ ) was drawn, thus allowing the determination of $b_{\mathrm{ph}}$ and $b_{\mathrm{NC}}$. The phase functions of the particles were computed using standard ranges of variation for the refractive indices of phytoplankton and noncovarying particles. The Junge exponent $\nu$ was considered as a variable parameter, while the particle radius interval of the size distribution was fixed to [0.1$200 \mu \mathrm{m}]$. The variations of the refractive indices and the Junge exponent $\nu$ mean that multidirectional effects of particles are included in the computations, which is consistent with the variability observed in the phase functions 
Table 1. Range of the Optical Properties Used for the Simulation of the Subsurface Rrs That Were Used to Train the $\mathrm{NN}^{\mathrm{a}}$

\begin{tabular}{lll}
\hline Optical Parameter & Minimum & Maximum \\
\hline$m_{\mathrm{ph}}$ & 1.05 & 1.10 \\
$m_{\mathrm{NC}}$ & 1.15 & 1.20 \\
$S_{\mathrm{NC}}, \mathrm{nm}^{-1}$ & 0.007 & 0.015 \\
$S_{\mathrm{CDOM}}, \mathrm{nm}^{-1}$ & 0.011 & 0.020 \\
$S_{\mathrm{bp}}, \mathrm{nm}^{-1}$ & 0 & 2 \\
$S_{\mathrm{bchl}}, \mathrm{nm}^{-1}$ & 0 & 2 \\
$S_{\mathrm{bsed}}, \mathrm{nm}^{-1}$ & 0 & 2 \\
$\nu$ & 3 & 5 \\
$r, \mu \mathrm{m}$ & 0.1 & 200 \\
$a_{\mathrm{ph}}, \mathrm{m}^{-1}$ & $6.12^{\mathrm{e}-03}$ & 0.904 \\
$a_{\mathrm{NC}}, \mathrm{m}^{-1}$ & $2.05^{\mathrm{e}-03}$ & 1.73 \\
$a_{\mathrm{CDOM}}, \mathrm{m}^{-1}$ & 0 & 1 \\
$b_{\mathrm{p}}, \mathrm{m}^{-1}$ & 0.076 & 21 \\
$b_{\mathrm{ph}}, \mathrm{m}^{-1}$ & 0 & 21 \\
$b_{\mathrm{NC}}, \mathrm{m}^{-1}$ & 0 & 21 \\
$b_{b p}, \mathrm{~m}^{-1}$ & $2.4 \mathrm{e}-04$ & 0.664 \\
$b_{\mathrm{bph}}, \mathrm{m}^{-1}$ & 0 & 0.40 \\
$b_{\mathrm{bNC}}, \mathrm{m}^{-1}$ & 0 & 0.70 \\
\hline
\end{tabular}

${ }^{\mathrm{a}}$ The IOP are reported for the wavelength $443 \mathrm{~nm} . m_{\mathrm{ph}}$ and $m_{\mathrm{NC}}$ are the refractive index of phytoplankton and noncovarying particles, respectively. $\nu$ is the Junge exponent of the size distribution, and $r$ is the radius of the size distribution.

in coastal areas [Chami et al., 2005, 2006]. Such important features are not necessarily accounted for in synthetic data sets in which a single particle phase function is used [Schiller and Doerffer, 1999; Gross et al., 2000]. Figure 1 shows some examples representing the variability over the data set of the unpolarized and polarized phase functions of the particles (i.e., terms $M_{11}$ and $M_{12}$ of the Mueller matrix $M$ ). The phase functions are plotted for two values of the refractive index, namely 1.05 and 1.20 , and two values of the Junge exponent, namely 3.5 and 4.5. To highlight the polarization effects of the particles, the polar-

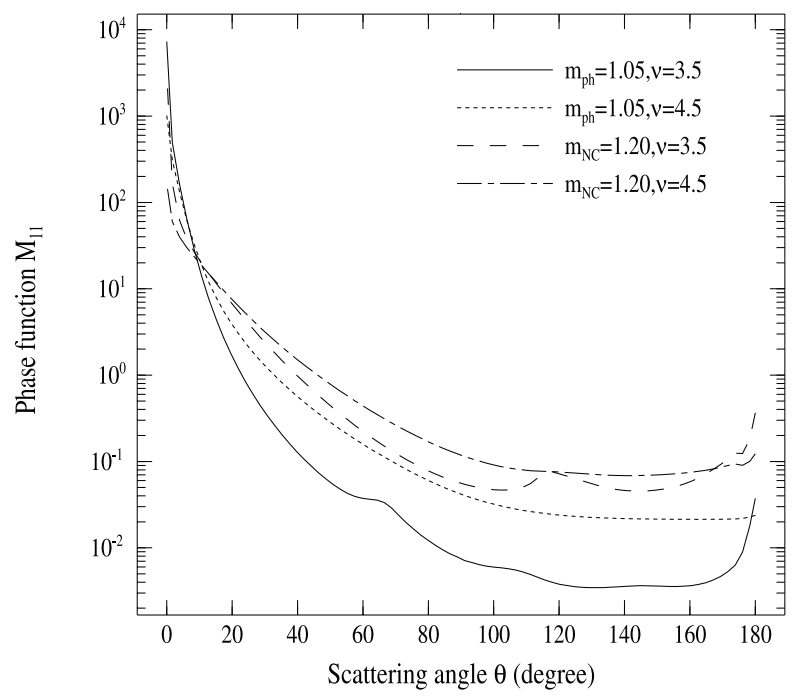

a ized phase function is normalized to the unpolarized phase function (i.e., the term $M_{12} / M_{11}$ is plotted in Figure $1 \mathrm{~b}$ ). Figure 1a shows that, given a size distribution, highly refractive particles exhibit backscattering efficiencies greater than biogenic particles. The normalized polarized phase functions show a minimum near a scattering angle of $90^{\circ}$ (Figure 1b). There are considerable differences in the height of the minima, ranging from $\sim-0.5\left(m_{\mathrm{NC}}=1.20, \nu=3.5\right)$ to $\sim-0.95\left(m_{\mathrm{ph}}=1.05, \nu=4.5\right)$. Such a variability is consistent with what has been found for phytoplankton samples grown in the laboratory ([Volten et al., 1998]; minima between -0.25 and -0.85 ; [Quinby-Hunt et al., 1989]; minima $\sim 0.8$ ). Note that the lowest simulated minima value compares well with the results found by Volten et al. [1998] for inorganic silt particles $(\sim-0.4)$ and for the species Emiliana huxleyi with coccoliths, thus indicating that our simulations satisfactorily match observations at large refractive index. The simulated polarized effects of the particles are also in agreement with what has been found for natural ocean water samples ([Voss and Fry, 1984]; minima between -0.6 and -0.8$)$. Therefore the polarization features of the particles that are taken into account in the simulations are meaningful.

[12] The IOP values at other wavelengths than $443 \mathrm{~nm}$ were determined by applying the abovementioned spectral models using randomly selected spectral slopes, except for the phytoplankton absorption coefficient $a_{\mathrm{ph}}(\lambda)$. In the latter case, the relationship that exists because of the packaging effect between the spectral shape of phytoplankton absorption coefficient and the magnitude of $a_{\mathrm{ph}}(443)$ was taken into account. The spectral shape of $a_{\mathrm{ph}}(\lambda)$ was determined by averaging the three absorption spectra taken in the COASTIOOC database, for which the measured value of $a_{\mathrm{ph}}(443)$ was the closest to the randomly selected value of $a_{\mathrm{ph}}(443)$.

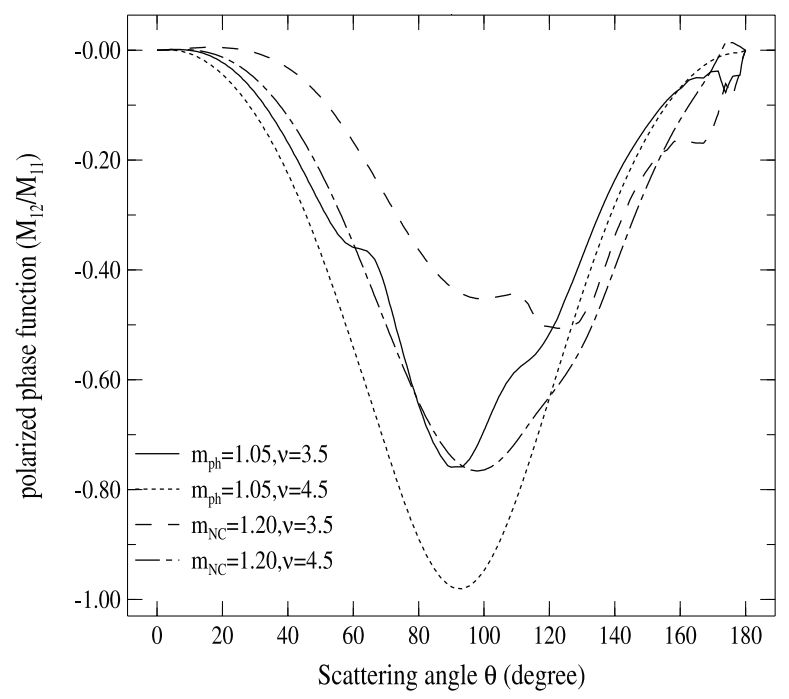

b

Figure 1. Examples of particulate phase functions used in the data set: (a) phase function (i.e., term $M_{11}$ of the Mueller matrix) and (b) polarized phase function normalized to the phase function (i.e., ratio $M_{12} /$ $\left.M_{11}\right)$. The phase functions are plotted for refractive indices values of 1.05 and 1.20 to be representative of phytoplankton and noncovarying particles and for Junge exponent values of 3.5 and 4.5. 


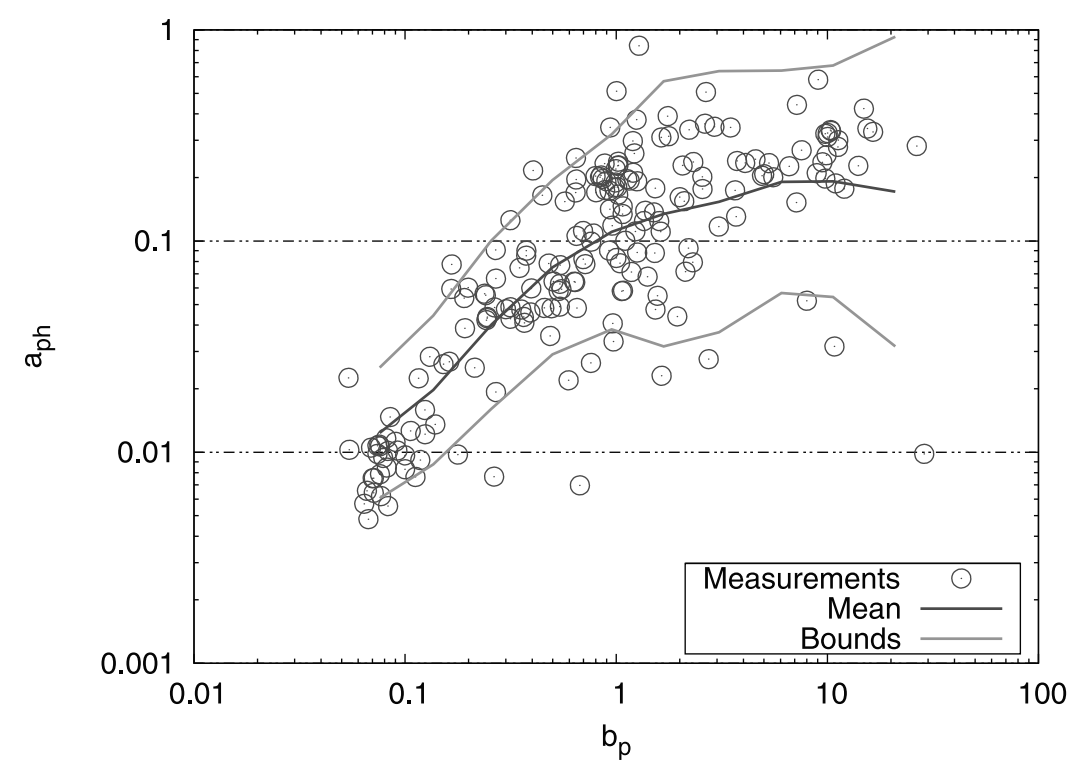

a

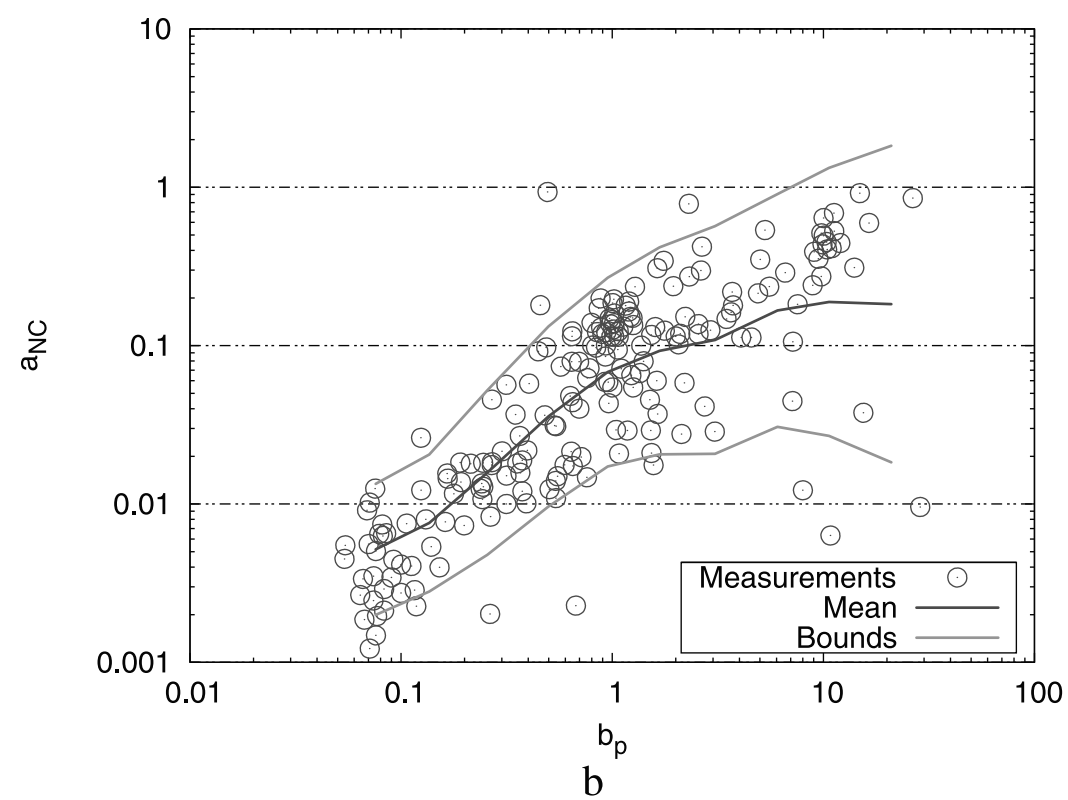

Figure 2. Covariations between (a) $a_{\mathrm{ph}}$ and $b_{\mathrm{p}}$ and (b) $a_{\mathrm{NC}}$ and $b_{\mathrm{p}}$ at $443 \mathrm{~nm}$ as observed during the COASTIOOC experiment. The covariation bounds were determined using the average values and the standard deviations of the measurements (see text). Units of the $x$ axis and $y$ axis are $\mathrm{m}^{-1}$.

[13] Despite the fact that each optical component is varied randomly within an appropriate range, it is necessary to account for optical constraints between IOP to exclude unrealistic combinations of IOP, such as cases of high absorption without any scattering. In our simulated data set, covariations between scattering and absorption were taken into account. The particle scattering coefficient $b_{\mathrm{p}}$ was not varied independently from the absorption coefficient of noncovarying particles $a_{\mathrm{NC}}$ and phytoplankton $a_{\mathrm{ph}}$. Thus, the minimum and maximum values of absorption coefficients of noncovarying particles and phytoplankton depend on the particle scattering coefficient $b_{\mathrm{p}}$, which is sampled first. The lower and upper limits of $a_{\mathrm{NC}}$ and $a_{\mathrm{ph}}$ are determined based on the COASTIOOC database as follows.
First, the entire range of variation of the logarithm of $b_{\mathrm{p}}$ is divided into 10 subranges. As a result, 10 clusters of each couple $\left[\log b_{\mathrm{p}}, \log a_{\mathrm{ph}}\right]$ and $\left[\log b_{\mathrm{p}}, \log a_{\mathrm{NC}}\right]$ are obtained. Note that a logarithmic scaling is used because low values prevail in the COASTIOOC measurements; such a scaling thus allows accounting for the natural dispersion of the data. Second, for each cluster, the mean value $\mu$ and the standard deviation $\sigma$ of the corresponding subset of $\log a_{\mathrm{ph}}$ or $\log a_{\mathrm{NC}}$ are computed. The upper and lower limits of $a_{\mathrm{NC}}$ and $a_{\mathrm{ph}}$ are then determined, adjusting a parameter $\alpha$ in the expressions $e^{(\mu+\alpha \sigma)}$ and $e^{(\mu-\alpha \sigma)}$, respectively. Here the limits of the domain of covariation between the particulate scattering and absorption coefficients are obtained using $\alpha=1.5$. Figure 2 shows the relations between $b_{\mathrm{p}}$ and $a_{\mathrm{NC}}$ and $b_{\mathrm{p}}$ and 
$a_{\mathrm{ph}}$ as observed during the COASTIOOC experiment. The upper and lower limits are centered on local mean values of the measurements. The covariation bounds satisfactorily encompass the majority of the data. The inclusion in the simulated data set of observations, optical constraints, and variability in the directional properties of the particles makes it representative of coastal water conditions.

\section{Architecture of the NN Algorithm}

[14] The input layer of the feedforward multilayer perceptron is designed to receive one Rrs spectrum. To analyze the influence of the directional and polarization effects on the IOP retrieval, three configurations of the input layer were studied. In the first configuration, the NN input layer corresponds to the Rrs spectrum, considering the radiance in the nadir direction only. Such a case is consistent with the usual way of measuring the in situ Rrs and is thus referred to as the standard configuration or case S. Since seven wavelengths were used, the input layer thus contains seven values in case $\mathrm{S}$. In the second configuration, the sensitivity of the algorithm to the multidirectionality of the Rrs is tested. Therefore the input layer consists of the Rrs spectrum obtained for nine scattering angles, namely $110^{\circ}, 120^{\circ}$, $125^{\circ}, 130^{\circ}, 135^{\circ}, 140^{\circ}, 150^{\circ}, 158^{\circ}$, and $165^{\circ}$. Such a configuration, hereafter referred to as case $\mathrm{M}$, is consistent with the characteristics of the PARASOL satellite sensor, which is able to observe a scene under 9 to 12 directions. In case $\mathrm{M}$, the input layer contains 63 neurons. The third configuration, hereafter referred to as case MP, is similar as case M except the polarized Rrs at 490 and $665 \mathrm{~nm}$ obtained in the nine previous directions is added to the input layer. Therefore the input layer contains 81 neurons in case MP.

[15] The output layer consists of the IOP to be retrieved, namely $a_{\mathrm{tot}}, a_{\mathrm{ph}}, a_{\mathrm{NC}}, a_{\mathrm{CDOM}}, b_{\mathrm{tot}}, b_{\mathrm{ph}}, b_{\mathrm{NC}}, b_{\mathrm{btot}}, b_{\mathrm{bph}}$, and $b_{\mathrm{bNC}}$. Actually, several tests were performed and the best results were obtained when each IOP is retrieved by separated NN models. Therefore for each NN model, the output layer only contains one neuron. One hidden layer was used, and the optimal number of hidden neurons (from 10 to 40) was determined experimentally for each model.

\section{Results}

[16] The NN algorithm was applied on a simulated data set (hereafter referred to as the validation set), though simulated with OSOA radiative transfer model, which is totally independent of the data used for training. Given the uncertainty in the Rrs measurements, the simulated reflectances are disturbed by adding 5\% noise, which typically corresponds to the radiometric performance of the commercially available instruments. Normally distributed errors are used here as a mean to disturb the Rrs in some reasonable manner. To evaluate the performance of the NN models, the relative root mean square (RRMS) error (equation (6)) was calculated. The RRMS is defined as:

$$
\mathrm{RRMS}=\sqrt{\frac{1}{n} \sum_{i=1}^{n}\left(\frac{\mathrm{IOP}_{\text {expected }}^{i}-\mathrm{IOP}_{\text {estimated }}^{i}}{\mathrm{IOP}_{\text {expected }}^{i}}\right)^{2}}
$$

where $n$ stands for the number of data, $\operatorname{IOP}_{\text {estimated }}^{i}$ stands for the $i$ th property derived from $\operatorname{Rrs}(\lambda)$ and $\mathrm{IOP}_{\text {expected }}^{i}$ for the $i$ th property known from simulation.

\subsection{IOP Retrieval for Case $S$}

[17] The IOP retrieval when the nadir-viewed subsurface Rrs spectrum is used to feed the NN input layer (case S) was studied first. Figure 3 shows the comparison between the derived $a_{\mathrm{tot}}$ and $b_{\mathrm{btot}}$ at $555 \mathrm{~nm}$ and their corresponding known values. Over the large dynamic range of the data set, $a_{\text {tot }}$ and $b_{\text {btot }}$ are retrieved within $\pm 7.4 \%$ and $\pm 9.8 \%$, respectively (see Table 2). The agreement is evident as shown by the high coefficient of determination $\left(R^{2}=0.96\right.$ and 0.98$)$ and the slope close to $1.0(0.96$ and 1.0$)$ for both IOP. Similar results were obtained at other wavelengths. Thus, the NN algorithm accurately retrieves those optical properties which are key parameters to determine the remote sensing reflectance (see equation (1)). However, the retrieval of the total scattering coefficient $b_{\text {tot }}$ is not as good as for $b_{\text {btot }}$ and $a_{\text {tot }}$ (RRMS $\sim 49.3 \%, R^{2}=0.84$, and a slope value of 0.87 ). A degradation of the performance was expected because $b_{\text {tot }}$ is a second-rate contributor to the Rrs signal compared with the total absorption and backscattering coefficients, which are explicitly related to the Rrs.

[18] When the total absorption is decomposed into the components of CDOM, noncovarying particles, and phytoplankton, the dispersion of the data in the scatterplot is much larger. As an example, Figures $4 a$ and $4 b$ show the retrieval of $a_{\mathrm{ph}}$ and $a_{\mathrm{NC}}$ at $555 \mathrm{~nm}$. The RRMS values for $a_{\mathrm{ph}}(555)$ $(20.2 \%)$ and $a_{\mathrm{NC}}(555)(18.3 \%)$ are nearly three times higher than the error calculated for the total absorption coefficient $a_{\mathrm{tot}}(555)$. Note that the performance of the model to retrieve $a_{\mathrm{ph}}$ and $a_{\mathrm{NC}}$ is more degraded at 443 compared with $555 \mathrm{~nm}$, with RRMS values of $34.3 \%$ and $35.4 \%$, respectively. A high dispersion is also observed regarding $a_{\mathrm{CDOM}}$ retrieval (RRMS $\sim 28.3 \%$ and $R^{2}=0.77$ at $443 \mathrm{~nm}$ ). A higher scatter was expected in the blue because phytoplankton, noncovarying particles, and dissolved organic matter exhibit overlapping absorption spectra, making them difficult to separate.

[19] The separation of the total backscattering coefficient into phytoplankton and noncovarying particles components also leads to much higher errors of retrieval compared with $b_{\mathrm{btot}}$ (Figures $4 \mathrm{c}$ and $4 \mathrm{~d}$ ). The RRMS values of $b_{\mathrm{bph}}$ and $b_{\mathrm{bNC}}$ were $61.7 \%$ and $44.3 \%$ at $555 \mathrm{~nm}$, which is about six and five times higher than the RRMS calculated for $b_{\text {btot }}$. Furthermore, the relationships significantly deviate from linearity, mostly in the range of the high values of the backscattering coefficients. The deviation from linearity of the relationships is more critical for the phytoplankton component for which the slope of the linear regression was 0.49 (0.85 for noncovarying particles) and the coefficient of determination was much lower (see Table 2). Similar results were obtained for the scattering coefficients $b_{\mathrm{ph}}$ and $b_{\mathrm{NC}}$. Because noncovarying particles have higher refractive indices and hence higher backscattering efficiencies than phytoplankton cells, they mostly contribute to the variations of the Rrs, thus explaining the better accuracy in the retrieval of their scattering properties.

\subsection{Influence of the Multidirectionality and Polarization}

[20] In this section, we evaluate the accuracy of the IOP retrieval when the multidirectional (referred as case $\mathrm{M}$ ) and 


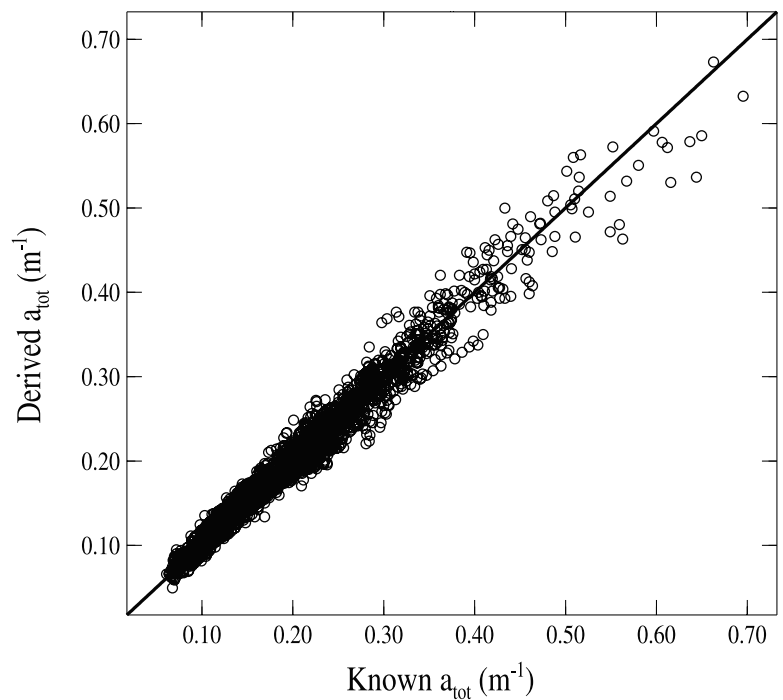

a

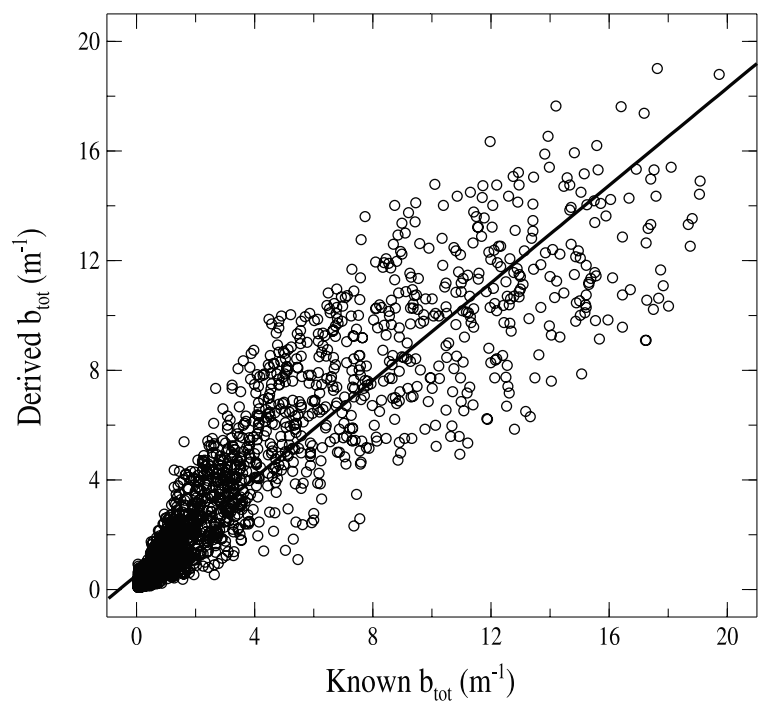

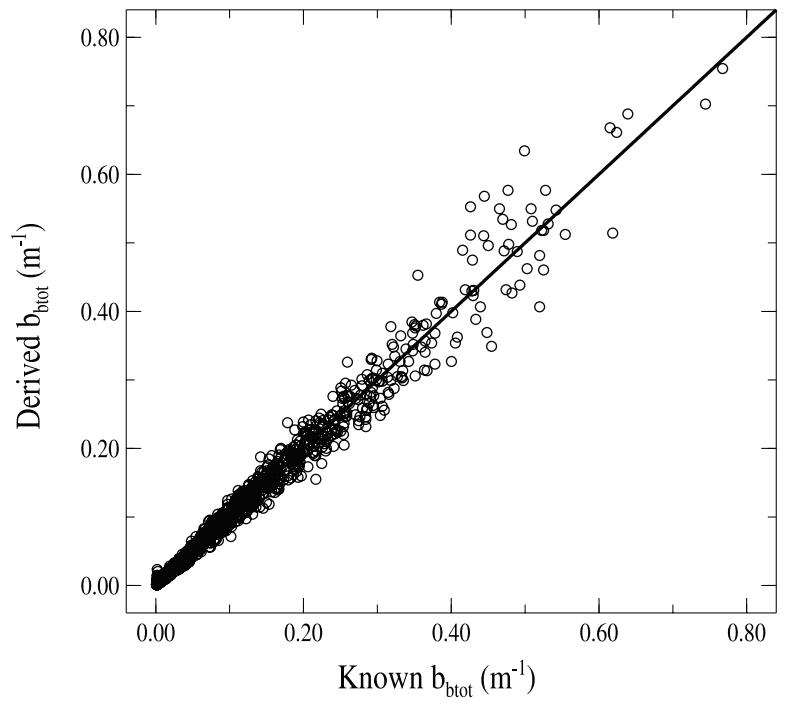

b

\section{$\mathrm{C}$}

Figure 3. Comparison between the retrieved and the known IOP at $555 \mathrm{~nm}$ : (a) $a_{\text {tot, }}$ (b) $b_{\text {btot }}$, and (c) $b_{\text {tot }}$. The nadir-viewed subsurface remote sensing reflectance spectra were inverted (case $\mathrm{S}$, see text).

polarized (referred as case MP) Rrs are taken into account in the inversion algorithm. To quantify the differences between case $\mathrm{S}$ and the other cases (M and MP), the following formulas was used (equation (7)):

$$
\Delta \mathrm{RRMS}_{k}=\frac{\left(\mathrm{RRMS}_{k}-\mathrm{RRMS}_{\mathrm{S}}\right)}{\mathrm{RRMS}_{\mathrm{S}}}
$$

where the subscript $k$ stands either for M or MP and the subscript $S$ stands for case S (i.e., nadir-viewed Rrs).

[21] Figure 5a shows the comparison of the retrieved $a_{\text {tot }}$ with the known values at $555 \mathrm{~nm}$. Table 3 reports the
Table 2. Performance of the NN Algorithm in Retrieving the IOP at $555 \mathrm{~nm}$ From the Simulated Data Set ${ }^{\mathrm{a}}$

\begin{tabular}{cccc}
\hline IOP at $555 \mathrm{~nm}$ & RRMS, \% & $R^{2}$ & $\begin{array}{c}\text { Slope of the } \\
\text { Linear Regression }\end{array}$ \\
\hline$a_{\text {tot }}$ & 7.4 & 0.96 & 0.96 \\
$b_{\text {btot }}$ & 9.8 & 0.98 & 1.00 \\
$b_{\text {tot }}$ & 49.3 & 0.84 & 0.87 \\
$a_{\text {ph }}$ & 20.2 & 0.80 & 0.79 \\
$a_{\mathrm{NC}}$ & 18.3 & 0.83 & 0.83 \\
$b_{\text {bph }}$ & 61.7 & 0.64 & 0.49 \\
$b_{\text {bNC }}$ & 44.4 & 0.86 & 0.85 \\
\hline
\end{tabular}

${ }^{\mathrm{a}}$ The coefficient of determination $R^{2}$ and the slope of the linear regression are also reported. 


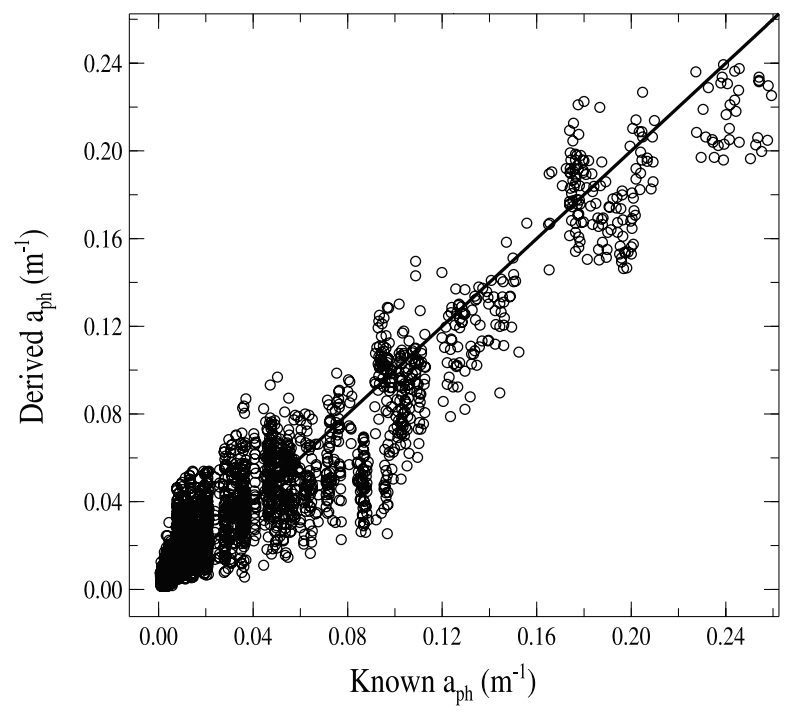

a

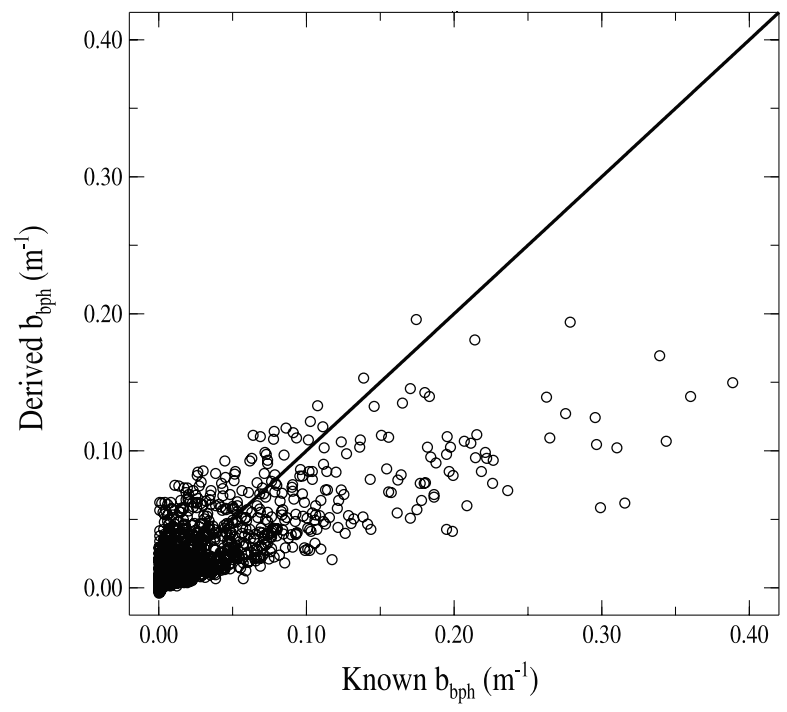

C

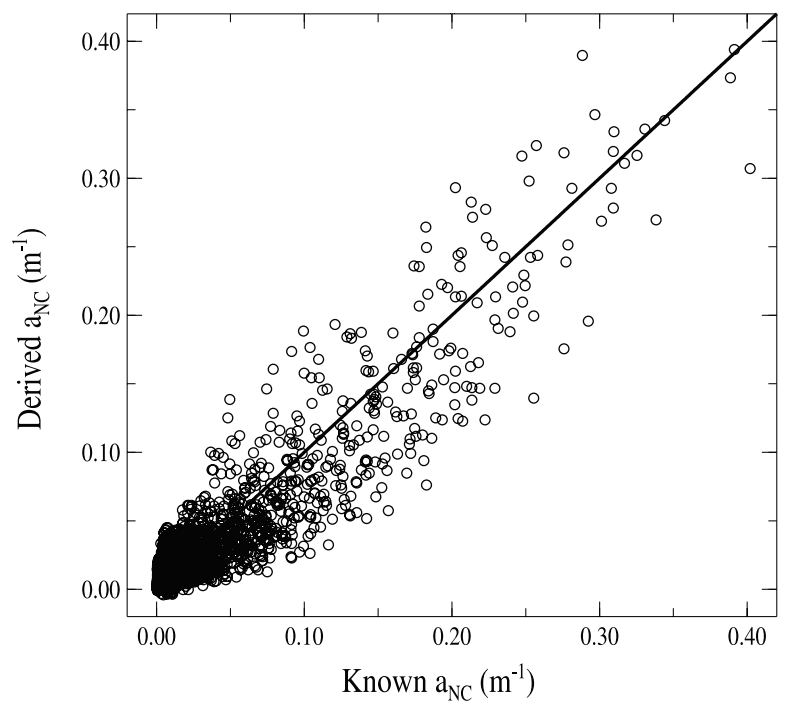

$\mathrm{b}$

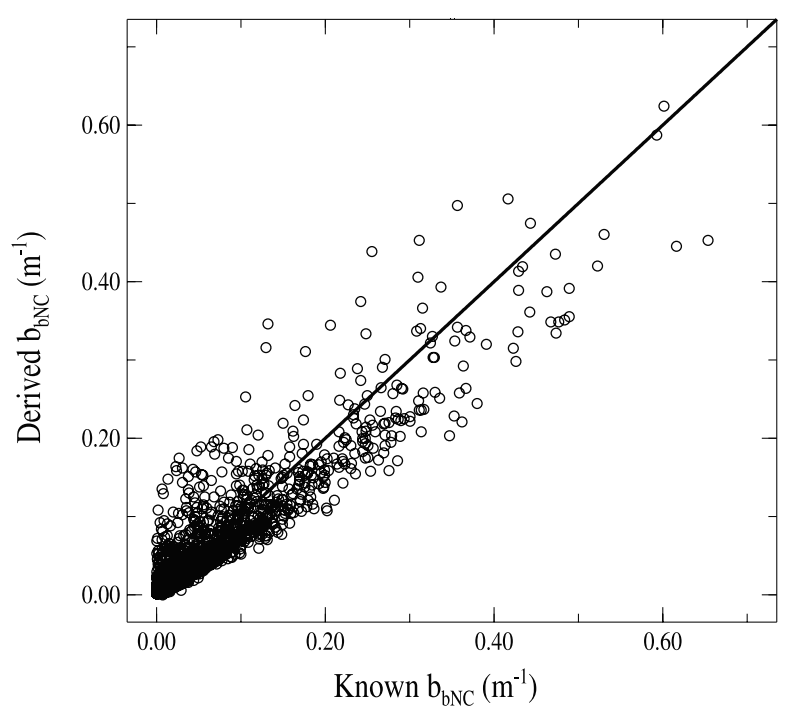

d

Figure 4. Same as Figure 3 but for the retrieval of the following IOP: (a) $a_{\mathrm{ph}}$, (b) $a_{\mathrm{NC}}$, (c) $b_{\mathrm{bph}}$, and (d) $b_{\mathrm{bNC}}$.

performance of the algorithm as well as $\triangle \mathrm{RRMS}_{\mathrm{M}}$ and $\triangle \mathrm{RRMS}$ MP. $a_{\text {tot }}$ is retrieved within an accuracy of $\pm 6 \%$ for cases $\mathrm{M}$ and MP, which is roughly $25 \%$ better than the accuracy obtained for case S. The use of the polarized Rrs slightly improves (by less than 7\%) case M. Similar results were observed at other wavelengths. Therefore it seems that the multidirectional reflectance induces a significant enhancement of the accuracy of $a_{\text {tot }}$ retrieval while the influence of the polarization is weak. As for $a_{\text {tot }}$, the retrieval of $a_{\mathrm{ph}}$ when accounting for the directionality and polarization in the inversion (Figure 5b) is still improved relatively to case $\mathrm{S}$. At $555 \mathrm{~nm}$, the accuracy increases by $\sim 35 \%$ when either case M or MP is considered. However, the improvement is twice lower at $443 \mathrm{~nm}(\sim 15 \%)$ (Table 4$)$.
The accuracy of $a_{\mathrm{CDOM}}$ retrieval is also enhanced by $15 \%$ at $443 \mathrm{~nm}$ (RRMS of $25 \%)$ when the multidirectional and the polarized Rrs are inverted. The accuracy of $a_{\mathrm{NC}}$ retrieval at $555 \mathrm{~nm}$ (Figure 5c) is increased by $8 \%$ and $21 \%$ for cases M and MP, respectively. However, the influence of the multidirectionality and the polarization on $a_{\mathrm{NC}}$ was very weak at shorter wavelengths $\left(\triangle \mathrm{RRMS}_{\mathrm{M}} \sim-0.8 \%\right.$ and $\triangle \mathrm{RRMS}_{\mathrm{MP}} \sim-1.4 \%$ at $443 \mathrm{~nm}$, Table 4 ).

[22] Figure 6 shows the retrieval of the backscattering coefficients $\left(b_{\mathrm{btot}}, b_{\mathrm{bph}}\right.$, and $\left.b_{\mathrm{bNC}}\right)$ at $555 \mathrm{~nm}$. Significant improvements in the accuracy of each IOP are observed. Typically, the introduction of the directionality in the algorithm enhances by $17 \%$ the retrieval of the backscattering coefficients of phytoplankton and noncovarying 


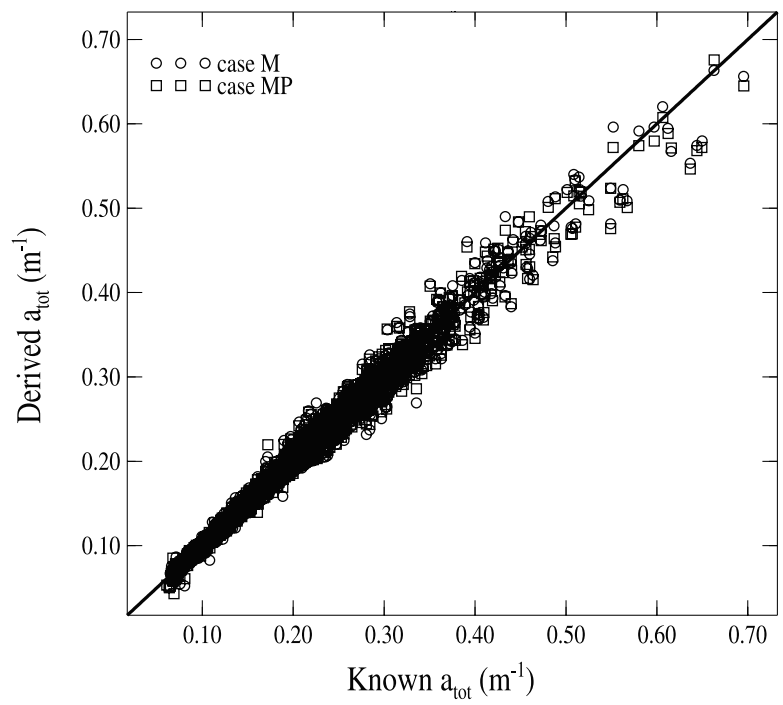

a

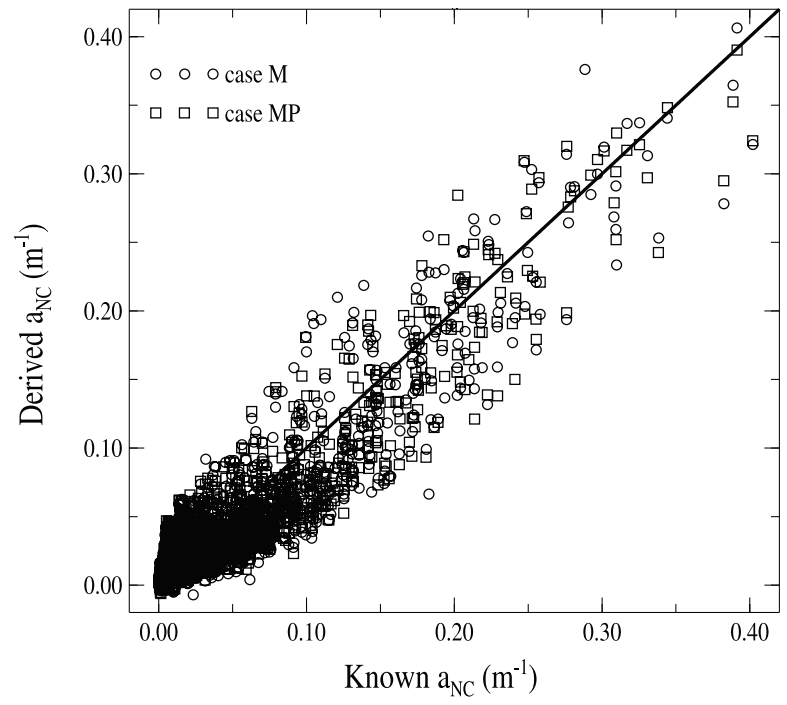

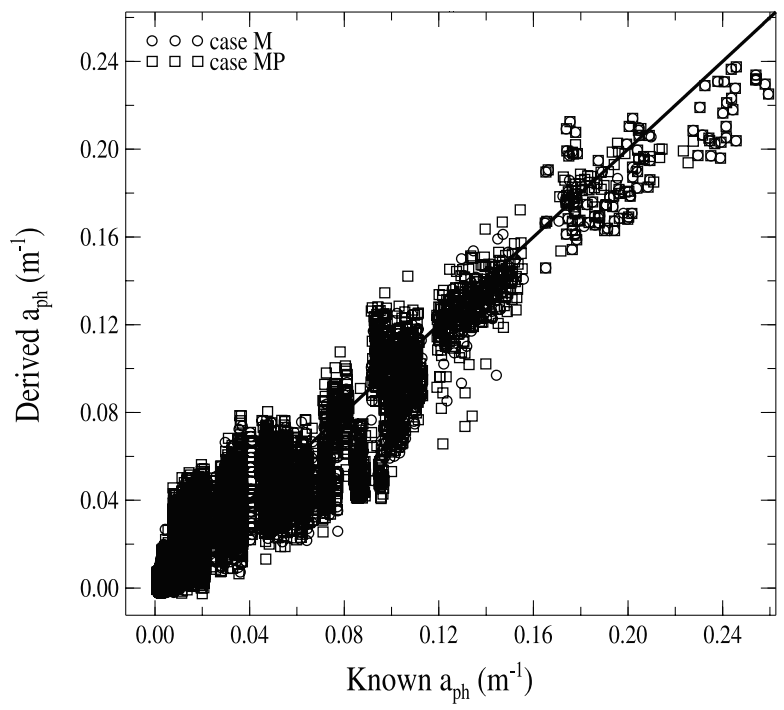

b

C

Figure 5. (a) Comparison between the retrieved and the known $a_{\text {tot }}$ at $555 \mathrm{~nm}$. The directional variations (case M) and the polarization of the reflectance (case MP, see text) were included in the inversion algorithm, (b) same as Figure 5a but for the retrieval of $a_{\mathrm{ph}}$, and (c) same as Figure 5a but for the retrieval of $a_{\mathrm{NC}}$.

particles and by a factor of 2 the retrieval of $b_{\text {btot }}$ (Table 3 ). The inclusion of the polarized Rrs induces a much greater increase of the performance of the algorithm, typically by a factor of $4\left(\triangle \mathrm{RRMS}_{\mathrm{MP}} \sim-75 \%\right)$ for $b_{\text {btot }}$ and by a factor of $3\left(\triangle \mathrm{RRMS}_{\mathrm{MP}} \sim-66 \%\right)$ for both $b_{\mathrm{bph}}$ and $b_{\mathrm{bNC}}$. Furthermore, the relationships get much closer to the linearity as the directionality and the polarization are taken into account. The change in the slope of the linear regression is more drastic for $b_{\mathrm{bph}}$ and to a lesser extent for $b_{\mathrm{bNC}}$. As an example, the values of the slope vary from 0.60 in case $\mathrm{M}$ to 0.99 in case MP for $b_{\mathrm{bph}}$ and from 0.89 in case M to 0.98 in case MP for $b_{\mathrm{bNC}}$. The scatter in the data is also significantly reduced. As a result, $b_{\mathrm{bph}}$ and $b_{\mathrm{bNC}}$ are retrieved within $\pm 23 \%$ and $\pm 15 \%$, respectively, in case MP (see Table 3). $b_{\text {btot }}$ is the best-retrieved parameter with an accuracy within $\pm 3 \%$.

[23] As for $b_{\text {btot }}$, the performance of the inversion for the retrieval of the total scattering coefficient $b_{\text {tot }}$ at $555 \mathrm{~nm}$ is significantly increased (typically, by a factor of 2 to 4 ) when comparing cases $\mathrm{M}$ and MP with case $\mathrm{S}$. The best agreement between the derived and the known $b_{\text {tot }}$ is obtained for case MP. The RRMS value is $11.5 \%$, which is very satisfactory since $b_{\text {tot }}$ plays a secondary role in the determination of the Rrs. As it was observed when dealing 
Table 3. Performance of the NN Algorithm in Retrieving the IOP at $555 \mathrm{~nm}$ When the Multidirectional (i.e., $\mathrm{RRMS}_{\mathrm{M}}$ ) and Polarized (i.e., RRMS $\left._{M P}\right)$ Rrs are Taken Into Account ${ }^{\mathrm{a}}$

\begin{tabular}{lcccc}
\hline IOP at & & & & \\
$555 \mathrm{~nm}$ & $\mathrm{RRMS}_{\mathrm{M}}, \%$ & RRMS $_{\mathrm{MP}} \%$ & $\Delta \mathrm{RMS}_{\mathrm{M}}, \%$ & $\Delta \mathrm{RMS}_{\mathrm{MP}}, \%$ \\
\hline$a_{\text {tot }}$ & 5.6 & 5.1 & -24.3 & -31.1 \\
$b_{\text {btot }}$ & 4.1 & 2.5 & -58.4 & -74.0 \\
$b_{\text {tot }}$ & 27.8 & 11.5 & -43.7 & -76.8 \\
$a_{\mathrm{ph}}$ & 12.8 & 13.1 & -36.7 & -35.1 \\
$a_{\mathrm{NC}}$ & 16.8 & 14.5 & -8.1 & -20.8 \\
$b_{\text {bph }}$ & 51.6 & 22.3 & -16.3 & -63.8 \\
$b_{\mathrm{bNC}}$ & 36.5 & 15.0 & -17.6 & -66.3 \\
$b_{\mathrm{ph}}$ & 65.2 & 26.4 & -21.8 & -68.3 \\
$b_{\mathrm{NC}}$ & 35.1 & 14.8 & -50.0 & -79.0 \\
\hline
\end{tabular}

${ }^{\mathrm{a}}$ The relative differences $\Delta \mathrm{RRMS}_{k}$ between (1) case $\mathrm{M}$ and $\mathrm{S}$ and (2) Case MP and S (see equation (7)) are also reported (in \%).

with backscattering coefficients, the multidirectionality and the polarization effects highly improve the performance of the inversion for $b_{\mathrm{ph}}$ and $b_{\mathrm{NC}}$, with a much greater influence of the polarization features (Table 3). Note that similar improvements are observed at other wavelengths (Figure 7). The use of the polarized Rrs allows decreasing significantly both the scatter of the data and the deviation from linearity (Figure 8). Therefore the scattering coefficients of phytoplankton and noncovarying particles are much better retrieved in turbid waters when the polarization is accounted for in the inversion algorithm than for case S. Our results also highlight that the algorithm provides a better accuracy with regard to $b_{\mathrm{NC}}$ (RRMS $\sim 15 \%$ ) compared with $b_{\mathrm{ph}}$ (RRMS $\sim 26 \%$ ).

\section{Discussion}

[24] As described above, the total absorption and backscattering coefficients are accurately retrieved in any cases despite the use of an optically complex and realistic simulated data set. These two optical parameters, which are the best retrieved compared with the other IOP, are the most robust variables in the inversion problem. This is not surprising because they are directly related to the variations of the remote sensing reflectance. The separation of the total IOP into contributions from water components (phytoplankton, noncovarying particles, and dissolved matter) induces a significant degradation of the performance of the algorithm. Similar conclusions were drawn by the IOCCG report $[I O C C G, 2006]$ based on a rigorous intercomparison exercise of different inverse methods, such as the NN algorithm developed for Medium Resolution Imaging Spectrometer (MERIS) [Doerffer and Schiller, 2006] or the semianalytic algorithm developed for Moderate Resolution Imaging Spectroradiometer (MODIS) [Carder et al., 1999]. The IOP retrieval of the different water components is less accurate because the inverse problem is not a bijective one from a mathematical viewpoint. Because of the additive property that characterizes the IOP, the sum of many combinations of IOP can produce the same total scattering, backscattering, or absorption coefficients and thus the same reflectance spectra. Therefore the inverse problem of ocean color is ambiguous inasmuch as many solutions may exist. The problem is much more difficult to solve when attempting to derive the IOP of each optically active water component. Thus, the performance of any inversion algorithm decreases. Note that the problem of ambiguities already exists when dealing with the retrieval of the total IOP. However, the number of parameters to be derived from the reflectance spectra is much lower than for the case of retrieving the separate IOP. Typically, on the basis of equation (1), two parameters are retrieved (i.e., $a_{\text {tot }}$ at $b_{\text {btot }}$ ) against five when the IOP are decomposed into water components (i.e., $a_{\mathrm{CDOM}}, a_{\mathrm{NC}}, a_{\mathrm{ph}}$, $b_{\mathrm{ph}}$, and $\left.b_{\mathrm{NC}}\right)$. Thus, the problem is less ambiguous in the case of the derivation of $a_{\text {tot }}$ and $b_{\mathrm{btot}}$, and a better accuracy is expected.

[25] The inclusions of the directional variations and the polarization at multiple angles of the Rrs significantly improve the performance of the inversion for all the IOP. However, these effects mostly influence the retrieval of the scattering and backscattering properties rather than the absorption coefficients. This is not surprising because (i) the scattering phase function of the particles is critical in determining the directional distribution of the reflectance and (ii) the polarization is an intrinsically single-scattering phenomenon. The improvement of the inversion performance due to the inclusion of the directional variations of the Rrs was in the range $15 \%-60 \%$. Such a significant influence of the directionality of the Rrs was expected since the entire shape of the volume scattering function matters to properly retrieve the IOP [Zaneveld, 1973]. The performance of the inversion to retrieve the scattering and backscattering properties is much more sensitive to the polarization component, which induces an increase in the accuracy of nearly $75 \%$ relatively to the single directional effects. On the basis of observations, Ivanoff et al. [1961] and Ivanoff [1975] found that, for a fixed value of the volume scattering function at $90^{\circ}$, the degree of polarization

Table 4. Performance of the NN Algorithm in Retrieving the IOP at $443 \mathrm{~nm}$ for Case $\mathrm{S}, \mathrm{M}$, and MP

\begin{tabular}{cccccc}
\hline IOP at $443 \mathrm{~nm}$ & $\mathrm{RRMS}_{\mathrm{S}}, \%$ & $\mathrm{RRMS}_{\mathrm{M}}, \%$ & $\mathrm{RRMS}_{\mathrm{MP}}, \%$ & $\Delta$ RRMS $_{\mathrm{M}}, \%$ & $\Delta$ RRMS $_{\mathrm{MP}}, \%$ \\
\hline$a_{\text {tot }}$ & 12.4 & 9.0 & 8.4 & -27.3 & -32.1 \\
$b_{\text {btot }}$ & 14.4 & 8.5 & 4.8 & -41.0 & -66.3 \\
$b_{\text {tot }}$ & 48.1 & 27.9 & 14.5 & -41.9 & -69.9 \\
$a_{\mathrm{ph}}$ & 34.3 & 29.4 & 29.1 & -14.3 & -15.4 \\
$a_{\mathrm{NC}}$ & 35.4 & 35.1 & 34.9 & -0.8 & -1.4 \\
$b_{\text {bph }}$ & 66.0 & 57.3 & 28.6 & -13.2 & -56.7 \\
$b_{\text {bNC }}$ & 45.5 & 32.1 & 15.7 & -29.5 & -65.6 \\
$b_{\mathrm{ph}}$ & 106.7 & 86.3 & 32.7 & -19.0 & -68.8 \\
$b_{\mathrm{NC}}$ & 87.9 & 51.9 & 20.5 & -41.0 & -76.7 \\
\hline
\end{tabular}

${ }^{\mathrm{a}}$ The relative differences $\triangle \mathrm{RRMS}_{k}$ between (1) case M and S and (2) case MP and S (see equation (7)) are also reported (in \%). 


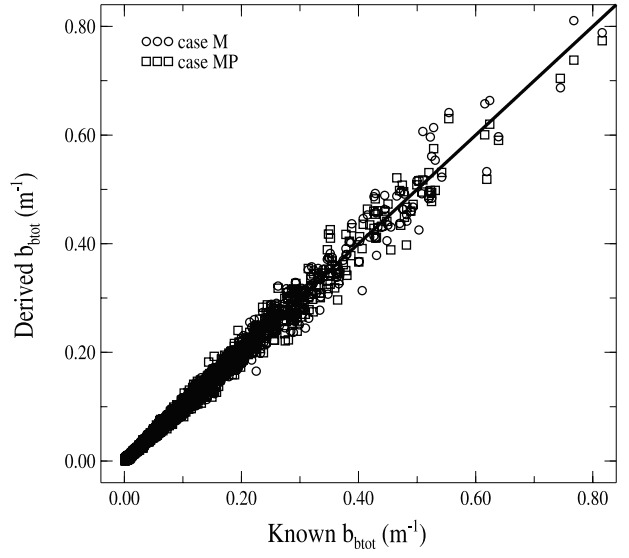

a

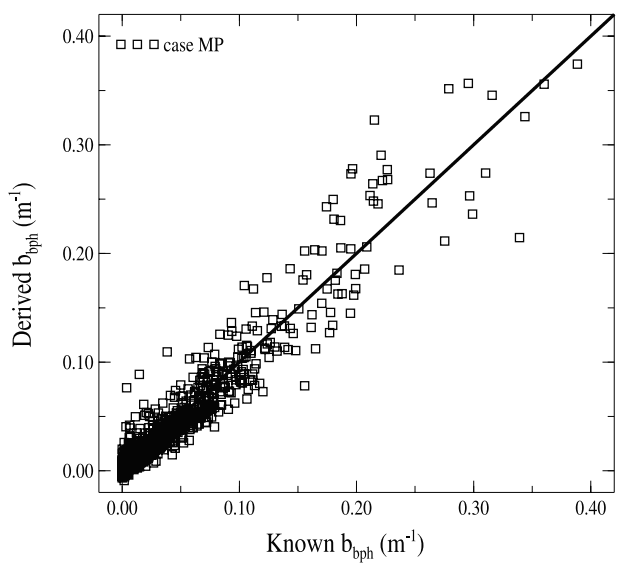

$\mathrm{C}$

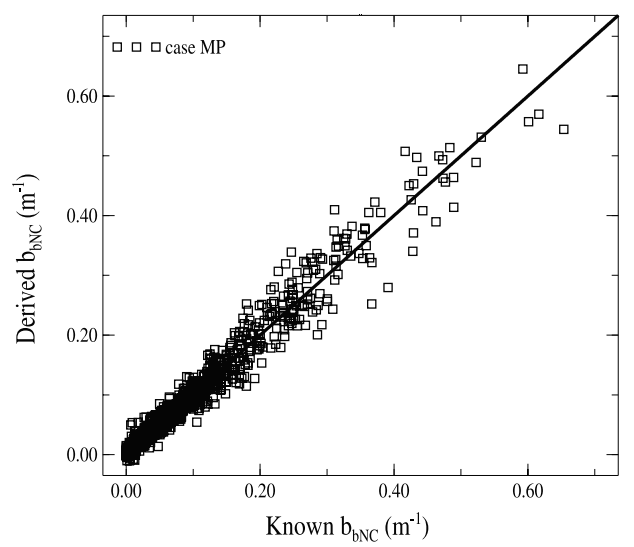

e

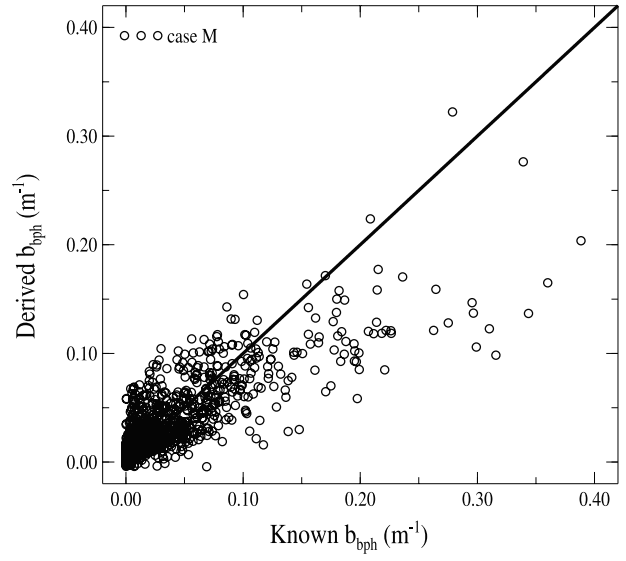

b

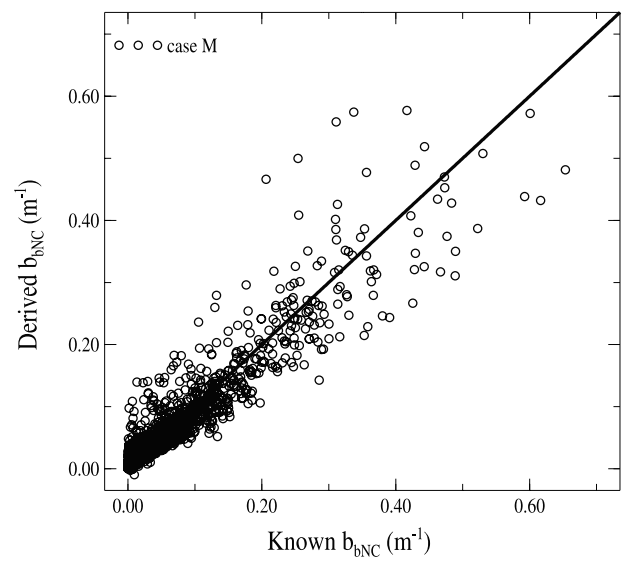

$\mathrm{d}$

Figure 6. Same as Figure 5 but for the retrieval of the following backscattering coefficients: (a) $b_{\text {btot }}$ and (b) $b_{\mathrm{bph}}:$ case $\mathrm{M}$, (c) $b_{\mathrm{bph}}:$ case MP, (d) $b_{\mathrm{bNC}}$ : case $\mathrm{M}$, and (e) $b_{\mathrm{bNC}}$ : case MP. 


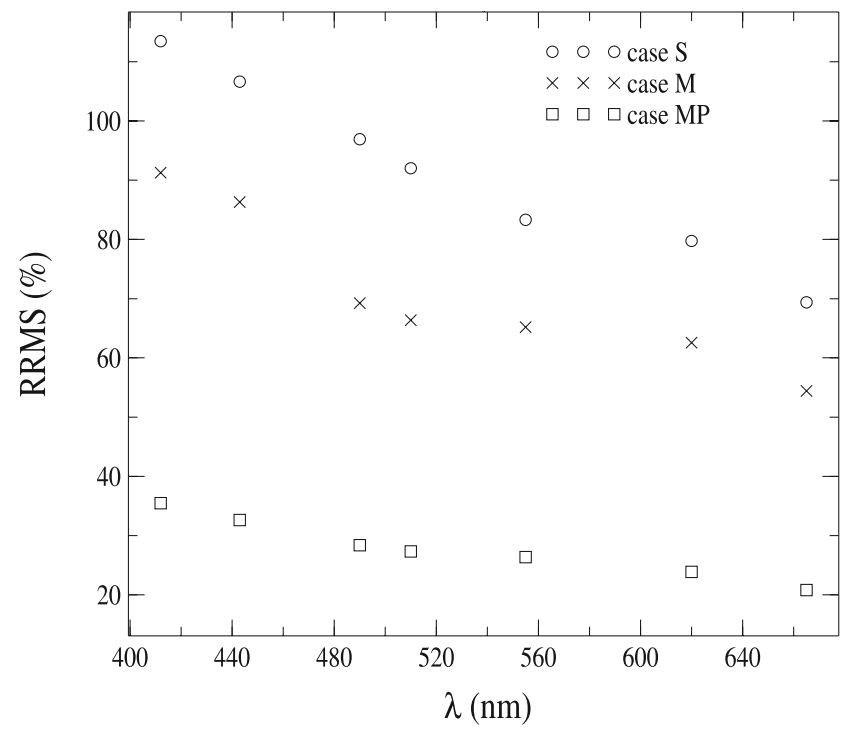

$\mathrm{a}$

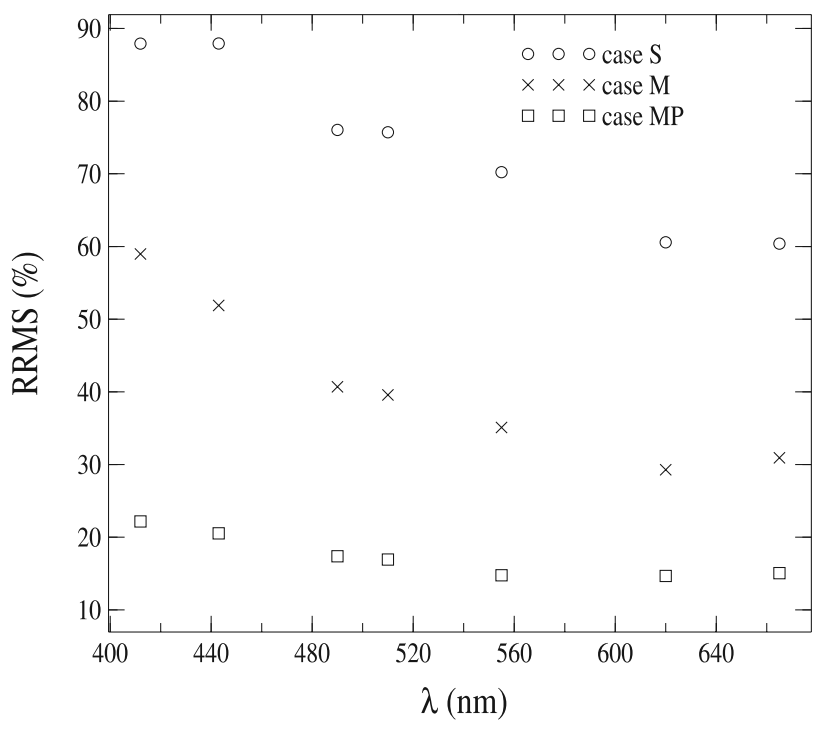

b

Figure 7. Spectral variation of the RRMS (in \%) obtained for the retrieval of (a) $b_{\mathrm{ph}}$ and (b) $b_{\mathrm{NC}}$. Cases S, M, and MP are reported.

can vary significantly according to the water mass. Ivanoff reported a variability of the degree of polarization ranging from $10 \%$ to $30 \%$ for a given volume scattering function. On this basis, the polarizing properties of the particles can be more sensitive to variations compared to the shape of the phase function, which is consistent with our findings regarding the higher influence of the polarization component in the performance of the inversion.

[26] Our results showed that the high values of the scattering and backscattering coefficients are much well retrieved using the polarized Rrs, as shown in Figures 6 and 7 , than lower values. The polarization of the radiation, which is primarily due to the molecular scattering, is significantly attenuated by multiple scattering. This phenomenon is called depolarization. The turbid waters, which are characterized by a prevailing multiple-scattering regime, thus contribute to strongly depolarize the radiation. Previous studies [Ivanoff et al., 1961; Morel, 1973] put in evidence that the maximum of the degree of polarization, which occurs at a scattering angle around $90^{\circ}$, is inversely correlated with the logarithm of the volume scattering function at $90^{\circ}$. Similarly, Chami [1997] found that the degree of polarization significantly decreases as the turbidity and the scattering coefficient increase. Furthermore, Chami et al. [2001] showed that the polarized remote sensing reflectance is highly sensitive to the concentration of suspended matter in the water mass. Therefore the polarization effects allow reducing drastically the number of ambiguities that exist in the reflectance spectra. The number of potential solutions of the inverse problem decreases, thus enhancing the efficiency of the algorithm. It should be highlighted that the use of polarized reflectance might have made the problem more ambiguous because of the increase of the number of inputs. Our study demonstrates that the polarization provides a relevant physical constraint, which is handled as useful information by the NN algorithm. Note that this was not true in the case of the derivation of the absorption properties.

[27] The retrieval of the scattering properties of each water component from the reflectance spectra is a challenging task. As it was previously observed (see section 5), the scattering properties of each water component are not correctly retrieved by the $\mathrm{NN}$ model in case $\mathrm{S}$, especially for turbid waters. Our results showed that the polarization allows discriminating the phytoplankton and noncovarying particles scattering and backscattering coefficients within a suitable accuracy ( $\sim 25 \%$ for phytoplankton and $\sim 15 \%$ for noncovarying particles). Because the polarization and the depolarization processes also depend on the composition of the particles (i.e., refractive index), differences in the accuracy of retrieval were expected between the noncovarying particles and phytoplankton component. Theoretically, the absolute value of the degree of polarization decreases as the refractive index increases (Figure 1b). Noncovarying particles, which are highly refractive particles, induce a higher depolarization relatively to phytoplankton cells. Nevertheless, they are also stronger backscatterers (Figure 1a); Chami et al. [2001] previously showed that noncovarying particles produce a polarized reflectance one order of magnitude greater than that of phytoplankton. As a result, the noncovarying particles are the main contributors to the variations of the polarized reflectance compared with phytoplankton. It is thus consistent to better improve the accuracy of the retrieval of the noncovarying particles scattering properties when the polarization is accounted for. Note that these results also corroborate the conclusions drawn by Volten et al. [1998] who suggested, based on measurements, that polarization may provide a useful tool to distinguish between inorganic and organic scattering material.

\section{Conclusion}

[28] In this paper, the influences of both the directional variations and the polarization of the reflectance on the 


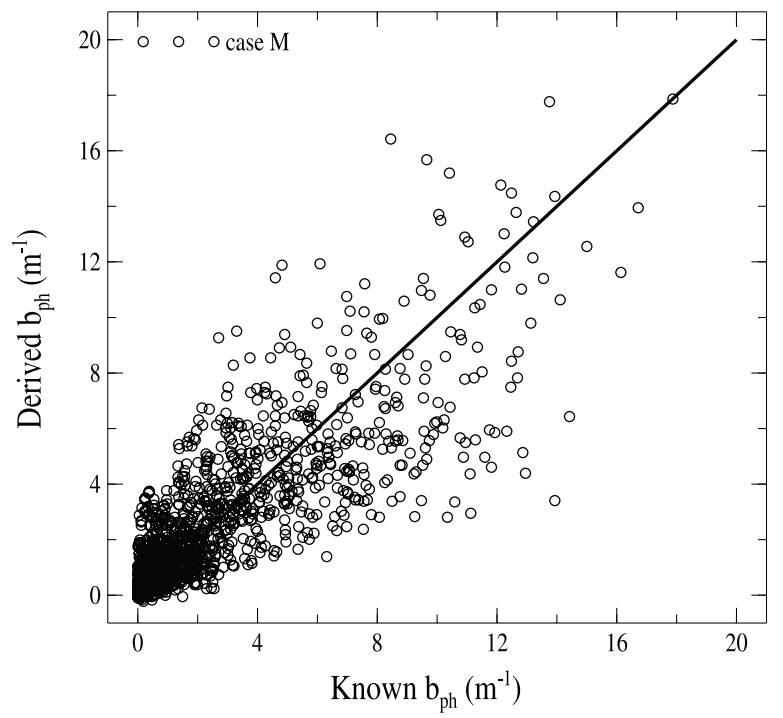

a

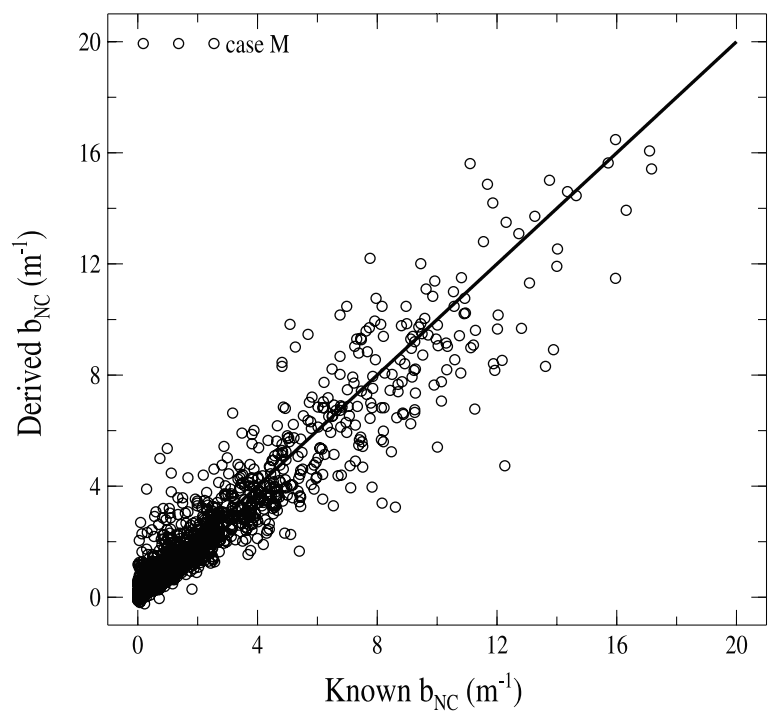

c

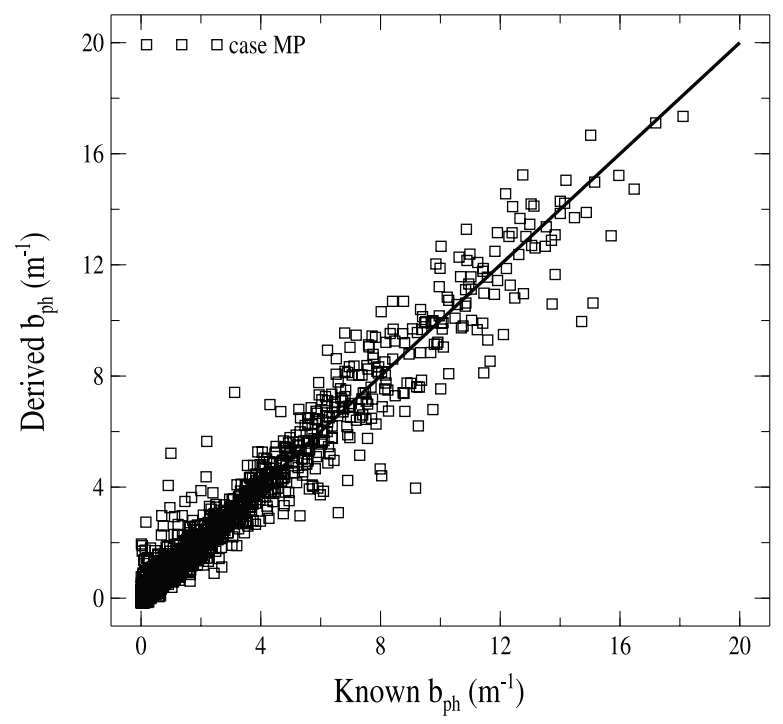

b

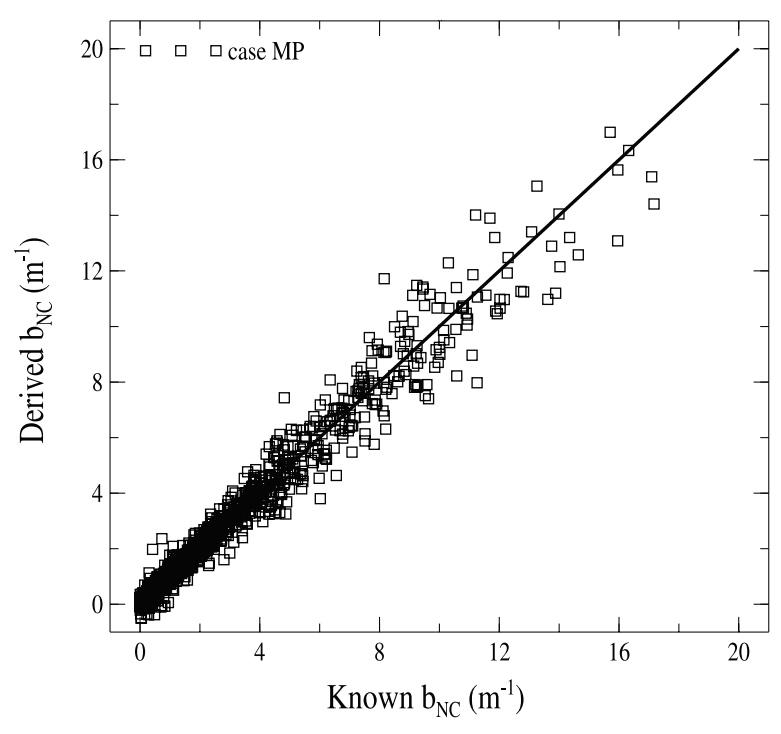

d

Figure 8. Same as Figure 5 but for the retrieval of the following scattering coefficients: (a) $b_{\mathrm{ph}}$ : case $\mathrm{M}$, (b) $b_{\mathrm{ph}}$ : case MP, (c) $b_{\mathrm{NC}}$ : case $\mathrm{M}$, and (d) $b_{\mathrm{NC}}$ : case MP.

retrieval of inherent optical properties of oceanic constituents in coastal waters were investigated. First, a neural network inversion procedure was developed using a synthetic data set. The data were simulated using a radiative transfer model that accounts for the polarization state of light in the ocean. The synthetic data set was also constrained by observations made in various representative coastal waters. In particular, the covariations that exist between the optical parameters were taken into account to exclude unrealistic combinations of IOP. The data set also included directional effects of marine particles through the inclusion of a high variability in the particulate phase function. It was demonstrated that the inversion algorithm can be applied satisfactorily to retrieve the total absorption and backscattering coefficients, which were the most robust variables. However, the separation of the total IOP into water components induced a significant degradation of the performances of the algorithm. This was explained by the fact that the inverse problem of ocean color is ill-posed; different combinations of each IOP could lead to similar reflectance spectra.

[29] The sensitivity of the algorithm to the directionality and to the polarization effects was then studied. It should be highlighted that this is the first time that the influence of the directionality and the polarization properties of the reflectance on the accuracy of the IOP retrieval is quanti- 
fied. Significant improvements were observed, especially regarding the scattering and backscattering coefficients. Typically, the inclusion of the directional variations of the reflectance induced an increase of the accuracy of the IOP retrieval from $15 \%$ to $60 \%$. When the polarization was taken into account, the improvement of the inversion was much greater regarding the retrieval of the scattering properties $(\sim 75 \%)$ while it was very small regarding the retrieval of the absorption coefficients. Both the scattering and backscattering coefficients of each water components were correctly retrieved (within $25 \%$ for phytoplankton and within $15 \%$ for noncovarying particles). Note that the scattering coefficients were correctly derived despite these IOP are second-rate contributors to the reflectance compared with the backscattering coefficients. Therefore the polarization is a robust physical constraint that can be used to increase significantly the efficiency of the inversion algorithms in coastal waters. A greater influence of the polarization information is expected in mineral-dominated waters where scattering processes prevail. Therefore the derivation of biogeochemical parameters from IOP in these optically complex waters should be significantly improved. Our results are highly encouraging in the prospect of the exploitation of the polarized data collected by the satellite sensor PARASOL (CNES), which still remains to be achieved. However, on the basis of this study, future efforts should also be directed in the development of in situ instrumentation able to measure the polarized reflectance in many directions to better analyze and interpret the variations of the ocean color in coastal waters.

\section{Notation and Abbreviation}

$a_{\text {tot }}$ Total absorption coefficient $\left(\mathrm{m}^{-1}\right)$

$a_{\mathrm{NC}}$ Absorption coefficient of noncovarying particles $\left(\mathrm{m}^{-1}\right)$

$a_{\mathrm{ph}} \quad$ Absorption coefficient of phytoplankton $\left(\mathrm{m}^{-1}\right)$

$a_{\text {CDOM }}$ Absorption coefficient of colored dissolved organic matter $\left(\mathrm{m}^{-1}\right)$

$b_{\text {tot }}$ Total scattering coefficient $\left(\mathrm{m}^{-1}\right)$

$b_{\mathrm{p}} \quad$ Particulate scattering coefficient $\left(\mathrm{m}^{-1}\right)$

$b_{\mathrm{NC}} \quad$ Scattering coefficient of noncovarying particles $\left(\mathrm{m}^{-1}\right)$

$b_{\mathrm{ph}} \quad$ Scattering coefficient of phytoplankton $\left(\mathrm{m}^{-1}\right)$

$b_{\text {btot }}$ Total backscattering coefficient $\left(\mathrm{m}^{-1}\right)$

$B_{\mathrm{bp}}$ Particulate backscattering coefficient $\left(\mathrm{m}^{-1}\right)$

$b_{\mathrm{bNC}}$ Backscattering coefficient of noncovarying particles $\left(\mathrm{m}^{-\mathrm{l}}\right)$

$b_{\mathrm{bph}}$ Backscattering coefficient of phytoplankton $\left(\mathrm{m}^{-1}\right)$

$G$ Proportionality factor between the reflectance and the ratio $b_{\text {btot }} / a_{\text {tot }}$

$\lambda$ Wavelength (nm)

$m_{\mathrm{NC}} \quad$ Refractive index of noncovarying particles

$m_{\text {ph }}$ Refractive index of phytoplankton

$\nu$ Junge exponent of the size distribution of the particles

$S_{\mathrm{CDOM}} \quad$ Spectral slope of $a_{\mathrm{CDOM}}\left(\mathrm{nm}^{-1}\right)$

$S_{\mathrm{NC}} \quad$ Spectral slope of $a_{\mathrm{NC}}\left(\mathrm{nm}^{-1}\right)$

$S_{\mathrm{bp}} \quad$ Spectral slope of $b_{\mathrm{p}}\left(\mathrm{nm}^{-1}\right)$
$S_{\mathrm{bp}} \quad$ Spectral slope of $b_{\mathrm{ph}}\left(\mathrm{nm}^{-1}\right)$

$S_{\mathrm{bNC}}$ Spectral slope of $b_{\mathrm{NC}}\left(\mathrm{nm}^{-1}\right)$

$0^{-}$Beneath the sea surface

Case S Standard configuration (nadir-viewed reflectance is inverted)

Case M Multidirectional configuration (reflectances in many directions are inverted)

Case MP Polarization configuration (total and polarized reflectances in many directions are inverted)

CDOM Colored Dissolved Organic Matter

CNES Centre National d'Etudes Spatiales

IOCCG International Ocean Colour Coordinating Group

IOP Inherent optical properties

$M$ Mueller matrix

$M_{11} \quad$ Unpolarized phase function

$M_{12}$ Polarized phase function

NN Neural network

OSOA Ordre Sucessifs Ocean Atmosphere

PARASOL Polarization and Anisotropy of Reflectances for Atmospheric Sciences Coupled with Observations From a Lidar

$R^{2}$ Coefficient of determination

RRMS Relative root mean square

Rrs Remote sensing reflectance

[30] Acknowledgments. This work was funded by the Centre National d'Etudes Spatiales (France). We are grateful to Marcel Babin for providing the COASTIOOC database. We would like to thank the anonymous reviewers for their relevant comments and suggestions.

\section{References}

Albert, A., and C. D. Mobley (2003), An analytical model for subsurface irradiance and remote sensing reflectance in deep and shallow case-2 waters, Opt. Express, 11, 2873-2890.

Babin, M., D. Stramski, G. Ferrari, H. Claustre, A. Bricaud, G. Obolensky, and N. Hoepffner (2003a), Variations in the light absorption coefficients of phytoplankton, nonalgal particles, and dissolved organic matter in coastal waters around Europe, J. Geophys. Res., 108(C7), 3211, doi:10.1029/2001JC000882.

Babin, M., A. Morel, V. Fournier-Sicre, F. Fell, and D. Stramski (2003b), Light scattering properties of marine particles in coastal and open ocean waters as related to the particle mass concentration, Limnol. Oceanogr., 48(2), 843-859.

Bricaud, A., A. Morel, and L. Prieur (1981), Absorption by dissolved organic matter of the sea (yellow substance) in the UV and visible domains, Limnol. Oceanogr., 26, 43-53.

Carder, K. L., F. R. Chen, Z. P. Lee, S. K. Hawes, and D. Kamykowski (1999), Semianalytic moderate-resolution imaging spectrometer algorithms for chlorophyll-a and absorption with bio-optical domains based on nitrate-depletion temperatures, J. Geophys. Res., 104, 5403-5421.

Chami, M. (1997), Développement d'un code de transfert radiatif pour le système océan-atmopshère. Application au Détroit du Pas de Calais, Ph.D. dissertation, 229 pp., Université du Littoral, France.

Chami, M., R. Santer, and E. Dilligeard (2001), Radiative transfer model for the computation of radiance and polarization in an ocean-atmosphere system: Polarization properties of suspended matter for remote sensing, Appl. Opt., 40(15), 2398-2416.

Chami, M., E. B. Shybanov, T. Y. Churilova, G. A. Khomenko, M. E.-G. Lee, O. V. Martynov, G. A. Berseneva, and G. K. Korotaev (2005), Optical properties of the particles in the Crimea coastal waters (Black Sea), J. Geophys. Res., 110, C11020, doi:10.1029/2005JC003008.

Chami, M., E. Marken, J. J. Stamnes, G. A. Khomenko, and G. K. Korotaev (2006), Variability of the relationship between the particulate backscattering coefficient and the volume scattering function measured at fixed angles, J. Geophys. Res., 111, C05013, doi:10.1029/2005JC003230. Doerffer, R., and H. Schiller (2006), The MERIS case 2 water algorithm, Int. J. Remote Sens., in press.

Garver, S. A., and D. Siegel (1997), Inherent optical property inversion of ocean color spectra and its biogeochemical interpretation. 1. Time series from the Sargasso Sea, J. Geophys. Res., 102, 18,607-18,625. 
Geisser, S. (1975), The predictive sample reuse method with applications, J. Am. Stat. Assoc., 70, 320-328.

Gross, L., S. Thiria, R. Frouin, and B. G. Mitchell (2000), Artificial neura networks for modelling the transfer function between marine reflectances and phytoplankton pigment concentration, J. Geophys. Res., 105, $3483-$ 3495 .

Hoge, F. E., and P. E. Lyon (1996), Satellite retrieval of inherent optical properties by linear matrix inversion of oceanic radiance models: An analysis of model and radiance measurement errors, J. Geophys. Res. $101,16,631-16,648$.

International Ocean Colour Coordinating Group (IOCCG) (2000), Remote sensing of ocean colour in coastal, and other optically-complex, waters, in Reports of the International Ocean Colour Coordinating Group, edited by S. Sathyendranath, No. 3, 140 pp. IOCCG, Dartmouth, Canada.

International Ocean Colour Coordinating Group (IOCCG) (2006), Remote sensing of inherent optical properties: Fundamentals, tests of algorithms, and applications, in Reports of the International Ocean Colour Coordinating Group, edited by Z. P. Lee, No. 5, IOCCG, Dartmouth, Canada. (Available at http://www.IOCCG.org/groups/OCAG_data.html).

Ivanoff, A. (1975), Introduction à l'océanographie: Propriétés physiques et chimiques des eaux de mer, vol. 2, Vuibert, Paris, 340pp., ISBN: 2-71176007-3.

Ivanoff, A., N. G. Jerlov, and T. H. Waterman (1961), A comparative study of irradiance, beam transmittance and scattering in the sea near Bermuda, Limnol. Oceanogr., 6, 129-148.

Jin, Z., and K. Stamnes (1994), Radiative transfer in nonuniformly refractive layered media such as the atmosphere-ocean system, Appl. Opt., 33, $431-443$.

Krogh, A., and J. A. Hertz (1992), A simple weight decay can improve generalization, in Advances in Neural Information Processing Systems 4 edited by J. E. Moody, S. J. Hanson, and R. P. Lippmann, pp. 950-957, Elsevier, New York.

Lee, Z. P., K. L. Carder, T. G. Peacock, C. O. Davis, and J. L. Mueller (1996a), Method to derive ocean absorption coefficients from remotesensing reflectance, Appl. Opt., 35, 453-462.

Lee, Z. P., K. L. Carder, and R. Arnone (2002), Deriving inherent optical properties from water color: A multi-band quasi-analytical algorithm for optically deep waters, Appl. Opt., 41, 5755-5772.

Maritorena, S., D. A. Siegel, and A. R. Peterson (2002), Optimization of a semianalytical ocean color model for global-scale applications, Appl. Opt., 41, 2705-2714.

Mobley, C. D. (1989), A numerical model for the computation of radiance distributions in natural waters with wind roughened surfaces, Limnol. Oceanogr., 34, 1473-1483.

Morel, A. (1973), Diffusion de la lumière par les eaux de mer: Résulats expérimentaux et approche théorique, in Optics of the Sea, Interface and In-water Transmission and Imaging, Lecture Ser. No. 61, pp. 3.1-1-
3.1-76, NATO Advisory Group for Aerospace Research and Development (AGARD), Neuilly-sur-Seine.

Morel, A., and B. Gentili (1996), Diffuse reflectance of oceanic waters. III. Implications of bi-directionality for the remote sensing problem, Appl. Opt., 35, 4850-4862.

Morel, A., D. Antoine, and B. Gentili (2002), Bidirectional reflectance of oceanic waters: Accounting for Raman emission and varying particle scattering phase function, Appl. Opt., 41, 6289-6306.

Park, Y. J., and K. Ruddick (2005), Model of remote sensing reflectance including bi-directional effects for case 1 and case 2 waters, Appl. Opt., 44(7), 1236-1249.

Pope, R., and E. Fry (1997), Absorption spectrum $(380-700 \mathrm{~nm})$ of pure waters: Integrating cavity measurements, Appl. Opt., 36, 8710-8723.

Quinby-Hunt, M. S., J. A. Hunt, K. D. Lofftus, and D. Shapiro (1989), Polarized light scattering studies of marine Chlorella, Limnol. Oceanogr, 34, 1587-1600.

Roesler, C. S., and E. Boss (2003), Spectral beam attenuation coefficient retrieved from ocean color inversion, Geophys. Res. Lett., 30(9), 1468, doi:10.1029/2002GL016185.

Roesler, C. S., and M. J. Perry (1995), In situ phytoplankton absorption, fluorescence emission, and particulate backscattering spectra determined from reflectance, J. Geophys. Res., 100(C7), 13,279-13,294.

Schiller, H., and R. Doerffer (1999), Neural network for emulation of an inverse model-operational derivation of case II water properties from MERIS data, Int. J. Remote Sens., 20, 1735-1746.

Schiller, H., and R. Doerffer (2005), Improved determination of coastal water constituent concentrations from MERIS data, IEEE Trans. Geosci. Remote Sens., 43, 1585-1591.

Shettle, E. P., and R. W. Fenn (1979), Models for the aerosols of the lower atmosphere and the effect of humidity variations on their optical properties, AFGL-Rep., TR-79-0214, Environmental Research Papers No. 676, $31 \mathrm{pp}$., Air Force Geophys. Lab., Bedford, Mass.

Volten, H., J. F. De Haan, J. W. Hovenier, R. Schreurs, W. Vassen, A. G. Dekker, H. J. Hoogenboom, F. Charlton, and R. Wouts (1998), Laboratory measurements of angular distributions of light scattered by phytoplankton and silt, Limnol. Oceanogr., 43(6), 1180-1197.

Voss, K. J., and E. S. Fry (1984), Measurement of the Mueller matrix for ocean water, Appl. Opt., 23(23), 4427-4439.

Zaneveld, J. R. V. (1973), New developments of the theory of radiative transfer in the ocean, in Optical Aspects of Oceanography, edited by N. G. Jerlov, pp. 121-134, Elsevier, New York.

M. Chami and M. D. Platel, Laboratoire Océanographie de Villefranche, UMR-CNRS 7093, Quai de la Darse, BP 08 Villefranche sur Mer 06230, France. (chami@obs-vlfr.fr) 